\title{
Seasonal Precipitation Predictability for the Northern Hemisphere Using Concurrent and Preseason Atmospheric Water Vapor Transport and Sea Surface Temperature $\mathscr{O}$
}

\author{
SHIDA GAO, ${ }^{\mathrm{a}, \mathrm{b}, \mathrm{c}, \mathrm{d}}$ PAN LiU, ${ }^{\mathrm{a}, \mathrm{b}}$ AND UPMANU LALL ${ }^{\mathrm{d}, \mathrm{e}}$ \\ ${ }^{a}$ State Key Laboratory of Water Resources and Hydropower Engineering Science, Wuhan University, Wuhan, China \\ ${ }^{\mathrm{b}}$ Hubei Provincial Key Lab of Water System Science for Sponge City Construction, Wuhan University, Wuhan, China \\ ${ }^{\mathrm{c}}$ Department of Ecology and Environment of Guangdong Province, Guangzhou, China \\ ${ }^{\mathrm{d}}$ Columbia Water Center, Columbia University, New York, New York \\ e Department of Earth and Environmental Engineering, Columbia University, New York, New York
}

(Manuscript received 28 April 2020, in final form 8 September 2020)

\begin{abstract}
Integrated atmospheric water vapor transport (IVT) is a determinant of global precipitation. In this paper, using the CERA-20C climate reanalysis dataset, we explore three questions in Northern Hemisphere precipitation for four seasons: 1) What is the covariability between the leading spatiotemporal modes of seasonal sea surface temperature (SST), the seasonal IVT, and the seasonal precipitation for the Northern Hemisphere? 2) How well can the leading spatial modes of seasonal precipitation be reconstructed from the leading modes of IVT and SST for the same season? 3) How well can the leading modes of precipitation for the next season be predicted from the leading modes of the current season's SST and IVT? Wavelet analyses identify covariation in the leading modes of seasonal precipitation and those of IVT and SST in the 2-8-yr band, with the highest amplitude in the March-May (MAM) season, and provide a firm physical explanation for the potential predictability. We find that a subset of the 10 leading principal components of the seasonal IVT and SST fields has significant trends in connections with seasonal precipitation modes, and provides an accurate statistical concurrent reconstruction and one-season-ahead forecast of the leading seasonal precipitation modes, thus providing a pathway to improving the understanding and prediction of precipitation extremes in the context of climate change attribution, seasonal and longer prediction, and climate change scenarios. The same-season reconstruction model can explain $76 \%$ of the variance, and the next-season forecast model can explain 58\% variance of hemispheric precipitation on average.
\end{abstract}

KEYWORDS: Atmosphere-land interaction; Atmosphere-ocean interaction; Seasonal forecasting; Reanalysis data

\section{Introduction}

Natural and anthropogenic climate variations determine spatiotemporal precipitation patterns and variability (Fischer and Knutti 2015; Polade et al. 2017; Swain et al. 2018). Recent research suggests that the intensity and frequency of precipitation is related in part to atmospheric water vapor transport (Lorente-Plazas et al. 2018; Pierce et al. 2013; Polade et al. 2014). Much of the discussion of climate change impacts is focused on how atmospheric water vapor and precipitation may scale with increasing temperature (Pendergrass et al. 2017; Trenberth 2011). There is also a recognition that changes in the large-scale atmospheric circulation and, more specifically, large-scale moisture transport and convergence, may determine the outcome for precipitation in many regions (Holman and Vavrus 2012; Mahoney et al. 2016; Viale et al. 2018).

Atmospheric rivers (ARs), defined as narrow and long corridors of concentrated moisture in the atmosphere ( $\mathrm{Zhu}$ and Newell 1994), can be hydrometeorological contributors to the precipitation and floods (Espinoza et al. 2018; Lavers et al. 2015; Neiman et al. 2008b; Zhu and Newell 1998). Similarly,

Supplemental information related to this paper is available at the Journals Online website: https://doi.org/10.1175/JHM-D-200107.s1.

Corresponding author: Pan Liu, liupan@whu.edu.cn tropical moisture exports (TMEs) can be a significant and recurrent contributor to extratropical precipitation (Knippertz and Wernli 2010; Knippertz et al. 2013; Nakamura et al. 2013; Steinschneider and Lall 2015). Their presence can be detected by an examination of the vertically integrated water vapor transport (IVT) (Neiman et al. 2008a). IVT is a measurement of water vapor advected horizontally in the atmosphere. The seasonal and interdecadal variations in the frequency, location and intensity of atmospheric water transports affect the hydroclimate in the western North America, and dominate the extreme daily precipitation events in eastern North America (Gao et al. 2015; Gershunov et al. 2017, 2019; Hagos et al. 2016; Payne and Magnusdottir 2015).

The role of teleconnections between the ocean and atmosphere on spatial and temporal variability in precipitation is well studied (Castillo et al. 2014; Ouyang et al. 2014). Precipitation teleconnection patterns related to the Pacific Ocean, the Indian Ocean, and the Atlantic Ocean at interannual and decadal time scales (Bjerknes 1969; Leathers et al. 1991; Perry et al. 2017) have been identified. Using both coupled ocean-atmosphere models and statistical methods, attempts have been made to forecast seasonal precipitation (Gershunov and Cayan 2003; Kobold and Sušelj 2005; Lu and Lall 2017; Pappenberger et al. 2005).

From past research we note that 1) the transport of moisture from oceanic sources plays an important role in the continental precipitation (Castillo et al. 2014; Gimeno 2014; Gimeno et al. 2010, 2012), 2) the variability and seasonality of moisture 
transport under global climate change need to be further investigated (Ent and Savenije 2013; Nieto et al. 2014), and 3) atmospheric water vapor transport links evaporation from the ocean and land (including moisture recycling mechanisms) to precipitation over the continents (Gershunov et al. 2017, 2019).

1) What is the nature of covariability between the leading spatiotemporal modes of seasonal sea surface temperature (SST), the seasonal IVT, and the seasonal precipitation for the Northern Hemisphere (NH)?

2) How well can the leading spatial modes of seasonal precipitation be reconstructed from the leading modes of IVT and SST for the same season?

3) How well can the leading modes of precipitation for the next season be predicted from the leading modes of the current season's SST and IVT?

Since the SST field represents the slowly evolving boundary conditions for the atmosphere and hence for IVT and precipitation, we are interested in seeing how the SST information translates into the seasonal statistics (specifically the mean field) of IVT and through that to the hemispheric precipitation, at the seasonal time scale. The covariation of these fields at interannual and longer time scales may then provide a basis for understanding if and why there is some predictability for the current and the subsequent season for precipitation given IVT and SST.

Climate reanalysis combines past weather and climate observations with physics-based models to reconstruct consistent time series of multiple climate variables (Kumar et al. 2013; Meehl et al. 2005). The European Centre for Medium-Range Weather Forecasts (ECMWF) recently launched its first ocean-atmosphere coupled reanalysis for the twentieth century, known as CERA-20C. The fields simulated by the reanalysis model provide a virtual laboratory for how the climate system has evolved over the last century, and in this virtual world one can explore potential chains of information transfer across different state variables that are not directly sampled in the real world (Liu et al. 2015; Shao et al. 2019).

The existing research on atmospheric water vapor transport and its connection to precipitation, has been typically at the daily time scale, or for events, or for climatological averages (Beck et al. 2017; Rivera et al. 2014). Here, we focus instead on the seasonal covariations in precipitation, IVT, and SST using the CERA-20C dataset, which is claimed to have much better performance than other ECMWF reanalysis datasets in reproducing SST and precipitation relationships and physically consistency in ocean and atmosphere conditions (Laloyaux et al. 2018). Our particular interest is to explore these covariations in these three fields in the context of low-frequency climate variability and the potential predictability across seasons.

Our major findings with respect to the research questions are 1) the spatial patterns of seasonal precipitation can be effectively reconstructed from the concurrent IVT and SST fields using principal component analysis (PCA) and Bayesian least absolute shrinkage and selection operator (LASSO) regression; 2) there is evidence of coherent interannual variability in the 2-8-yr frequency band for most seasons for the SST, IVT, and precipitation, confirming the link and the utility of understanding the associated dynamics such as ENSO; and 3) depending on the season, the leading modes of Northern Hemisphere seasonal precipitation can be forecast quite well using linear models from the previous season's SST and IVT for the CERA-20C reanalysis, suggesting potential precipitation predictability in that virtual world.

The paper is organized as follows. Sections 2 and 3 describe the datasets and the analytical methods. Section 4 reports on the analysis of the three research questions: section $4 \mathrm{a}$ discusses the time evolution and spatial patterns of the three fields for each season, section $4 \mathrm{~b}$ reports on the precipitation reconstruction using concurrent IVT and SST modes, and section $4 \mathrm{c}$ reports on the season ahead forecast models' performance. Section 5 summarizes the key findings.

In this paper we explore the development of one season ahead forecasting model for hemispheric precipitation fields using IVT and SST derived from the CERA-20C reanalysis dataset. The current work provides a basis for exploring the utility of such forecasts, as well as an application to seasonal to decadal forecasting of precipitation. It also provides diagnostics for the evaluation of the relative importance of temperature scaling versus circulation for precipitation changes.

\section{CERA-20C reanalysis dataset}

The precipitation, atmospheric pressure, and humidity and SST fields with a resolution of $1^{\circ}$ latitude $\times 1^{\circ}$ longitude from 1901 to 2010 from the CERA-20C reanalysis dataset (https:// apps.ecmwf.int/datasets/) were used to explore the connections between the Northern Hemisphere precipitation, IVT, and SST. The selected region ranges from $5^{\circ} \mathrm{S}$ to $70^{\circ} \mathrm{N}$ over all longitudes. Atmospheric pressure and humidity fields were used to calculate IVT. The IVT is calculated by the specific humidity $(q)$ and horizontal and vertical wind components $(u$ and $v$ ) integrated from 1000 to $300 \mathrm{hPa}$ (Neiman et al. 2008b):

$$
\mathrm{IVT}=\sqrt{\left(\frac{1}{g} \int_{300}^{1000} q u d p\right)^{2}+\left(\frac{1}{g} \int_{300}^{1000} q v d p\right)^{2}}
$$

where IVT is the integrated water vapor transport; $g$ is the gravity of Earth, chosen as $9.8 \mathrm{~m} \mathrm{~s}^{-2}$ here; $u$ and $v$ are layeraveraged horizontal and meridional wind components $\left(\mathrm{m} \mathrm{s}^{-1}\right)$; $q$ is layer-averaged specific humidity $\left(\mathrm{kg} \mathrm{kg}^{-1}\right)$; and $d p$ is the pressure difference between two contiguous layers $(\mathrm{hPa})$.

The daily precipitation, SST, and IVT data are converted at each spatial grid cell into the mean values for each of four seasons, March-May (MAM), June-August (JJA), SeptemberNovember (SON), and December-February (DJF). Subsequent analyses are performed using these seasonal gridded data, separately for each of the seasons.

\section{Methods}

Figure 1 provides an overview of the methods used to address the research questions. Each seasonal field is first analyzed using PCA to find the leading spatial modes. Next, the correlation across the leading principal components (PCs) of 


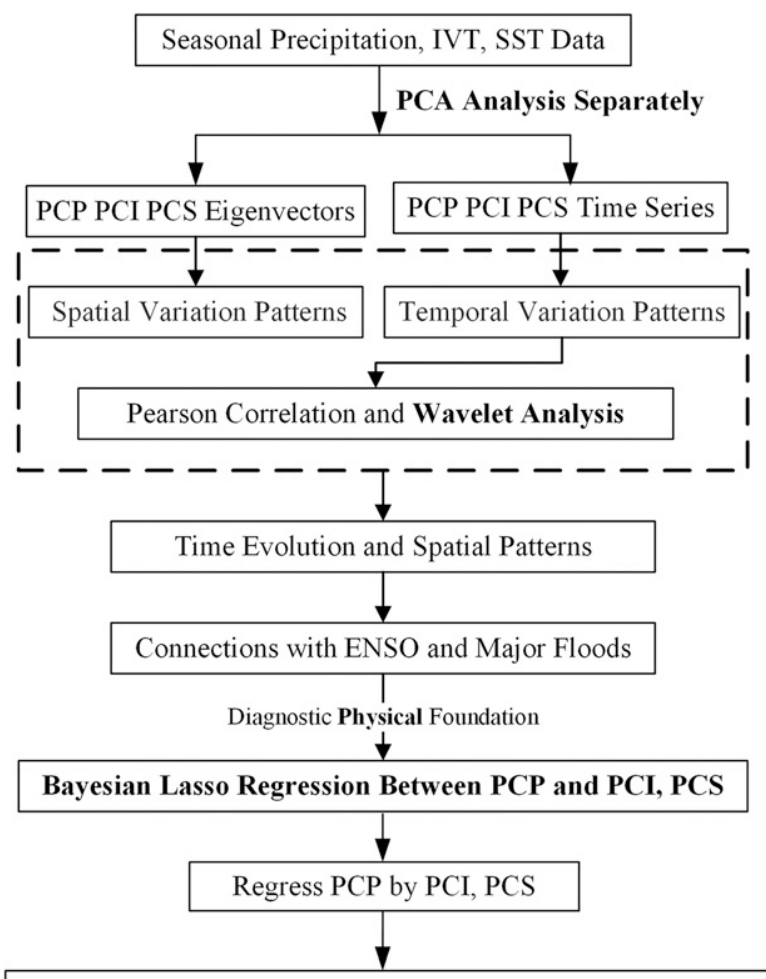

Precipitation Reconstruction $=\mathbf{P C P} \cdot$ Eigenvectors $^{\top}+\mathrm{Mean}$
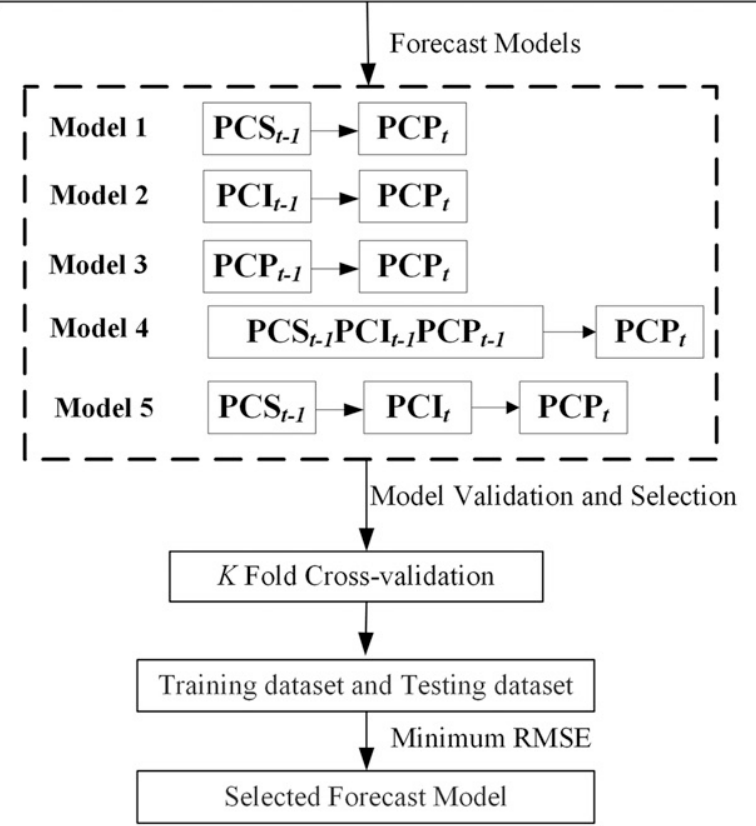

FIG. 1. Flowchart of precipitation reconstruct and forecast procedures. The precipitation, IVT, and SST fields are first analyzed for time evolution and spatial patterns. Spatial patterns and correlation coefficients between precipitation's 10 leading principal components (PCPs), IVT's 10 leading principal components (PCIs), and SST's 10 leading principal components (PCSs) are used to establish the foundations for precipitation's reconstruction. Each seasonal PCP is regressed on the season's PCI and PCS's using Bayesian LASSO regression and then the seasonal full each field is assessed to understand how the spatial modes of precipitation relate to the spatial modes of IVT or SST for the same season. Each principal component time series is also analyzed using wavelets to identify frequency bands for which the temporal variations have significant variance with respect to a null hypothesis of white noise or red noise. Wavelet coherence analysis is then pursued for the PCs of one field versus the other (e.g., precipitation versus IVT or SST modes) to assess if an apparently significant interannual frequency band in one field (e.g., precipitation) exhibits statistically significant coherence with a putative driving variable (e.g., IVT or SST) for the same frequency band.

The wavelet analysis can discover which season has the highest variance explained in some of the key frequency bands at the interannual and decadal time scale, whether it is present in the SST and then in the IVT and in the precipitation.

The spatial patterns of the precipitation PCs (PCPs), IVT PCs (PCIs), and SST PCs (PCSs) for the whole period in four seasons were selected and then compared, and the wavelet coherences between each PCs were investigated. The PC time series with strong coherence were then selected and classified by the state (El Niño, La Niña, and neutral) of El NiñoSouthern Oscillation (ENSO) years. In each case, we also explored the implication for major floods globally or concurrent floods across many regions. Following the strongest variance season analysis, the other seasons were performed following the same approach. This diagnostic analysis was used to support the argument for the potential causality or predictability of seasonal precipitation through the atmospheric circulation and SST evolution mechanisms.

Once these diagnostic relationships were established, a multivariate, robust, Bayesian linear regression model using LASSO is used to relate the leading PCs of precipitation for the current or the next season to the leading PCs of IVT and SST for the current season. For the season ahead forecast model, we considered several possible model structures as illustrated in the figure, and chose the best model using $K$-fold cross validation. The candidate models considered included 1 ) the prior season SST; 2) the prior season IVT; 3) prior season precipitation; 4) prior season SST, precipitation, and IVT; and 5) a model using prior season SST to predict current season IVT which is then used to predict current season precipitation.

\section{a. Principal component analysis}

PCA is a mathematical orthogonal linear transformation that transforms the original data into a reduced dimension creating new uncorrelated variables that successively maximize variance (Demšar et al. 2013). The resulting PCs are uncorrelated time series associated with corresponding spatial eigenvectors that indicate the participation of the locations in each PC or spatial pattern. PCs represent the dominant linear

$\longleftarrow$

precipitation fields are then reconstructed; $\mathbf{P} \mathbf{C P}_{t-1}, \mathbf{P C l}_{t-1}$, and $\mathbf{P} \mathbf{C S}_{t-1}$ are used as predictors to forecast $\mathbf{P} \mathbf{C P}_{t}$ in different models, which are selected by cross-validation method and verified by wavelet analysis. 
spatial and temporal patterns of variabilities in the order of decreasing importance.

In this paper, PCA was applied to the gridded seasonal precipitation and IVT and SST datasets separately, using the covariance matrix for each field. A subset of $k$ PCs of each field was retained (Greene et al. 2019).

For PCPs, PCIs, and PCSs, their linear correlations (across each field) are computed using Pearson correlation coefficient as

$$
\rho_{X, Y}=\frac{E\left[\left(X-\mu_{X}\right)\left(Y-\mu_{Y}\right)\right]}{\sigma_{X} \sigma_{Y}},
$$

where $X$ is one of PCPs; $Y$ is one of PCIs or PCSs; $\sigma_{X}$ and $\sigma_{Y}$ are the standard deviations; $\mu_{X}$ and $\mu_{Y}$ are the average value of $X$ and $Y$, respectively.

\section{b. Wavelet analysis}

Wavelet analysis provides an effective approach for timefrequency analyses relative to windowed Fourier transforms (Sang 2013; Torrence and Compo 1998). The continuous wavelet transform (WT) is used for revealing series temporal characteristics and analyzing localized intermittent oscillations under multitemporal scales, with the mother wavelet chosen as "Morlet" (Labat 2005).

The wavelet transformation of an observed data, $x(t)$ with respect to the Morlet wavelet, $\psi$ as the convolution integral (Labat 2005):

$$
Z(t, b)=\frac{1}{\sqrt{b}} \int_{0}^{n} x(t) \psi^{*}\left(\frac{n-t}{b}\right) d n
$$

where $\psi^{*}$ equals to the complex conjugate of $\psi, n$ is the total length of the time series, and $Z(t, b)$ is a wavelet spectrum of the decomposed time series at scale $b$ and time $t$.

The wavelet spectrum is integrated over time to obtain the global wavelet spectrum (GWS). The wavelet coherence (WTC) was computed to assess the in coherence and phase by time scale for any two PCs (Grinsted et al. 2004), for precipitation and IVT and SST to identify coherent evolutionary dynamics. The wavelet coherence of two-time series is defined as

$$
R_{n}^{2}(s)=\frac{\left|S\left[s^{-1} W_{n}^{X Y}(s)\right]\right|^{2}}{S\left[s^{-1}\left|W_{n}^{X}(s)\right|^{2}\right] S\left[s^{-1}\left|W_{n}^{Y}(s)\right|^{2}\right]},
$$

where $W_{n}^{X}(s)$ is the wavelet power of time series $X, W_{n}^{Y}(s)$ is the wavelet power of time series $Y, X$ and $Y$ are chosen PCPs and PCIs and PCSs in practical calculations, $S$ is a smoothing operator, and $s$ represents scale.

\section{c. Reconstruction models using concurrent predictors}

In the seasonal precipitation reconstruction models, we relate each of the leading $k$ PCPs to $k$ PCIs and the $k$ PCSs in same seasons using a linear regression model:

$$
\mathbf{P C P}_{t}=\mathbf{P C X}_{t} \boldsymbol{\beta}_{t}+\varepsilon_{t},
$$

where $\mathbf{P} \mathbf{C} \mathbf{P}_{t}$ is an $k \times n$ matrix, $n$ equals to the length of time period, $t$ represents the season. The matrix $\mathbf{P C X}$ refers to $\mathbf{P C l}{ }_{t}$ and $\mathbf{P C S}$ in the same season $(\mathbf{P C P}$ is regressed by $\mathbf{P C l}$ and
$\mathbf{P C S}_{t}$ separately). The leading $k$ PCPs are regressed separately by $k \mathbf{P C X}$, and $k$ is chosen same for each field and season based on the accounted variance threshold (subsequent PCs add less than $2 \%$ ). The $\boldsymbol{\beta}_{\tau}$ is a matrix of regression coefficients and $\boldsymbol{\varepsilon}_{\tau}$ is a matrix of residuals from the regression.

As PCPs are not related to all the $k$ PCX, we only need a subset of these predictors and choose the LASSO rather than best subset regression. The result will be a subset of the PCSs and PCIs that can best explain each PCP for the same season.

LASSO was used shrink the set of candidate predictors and to estimate the $\boldsymbol{\beta}$. It solves for the "optimal" model by minimizing the residual sum of squares, while penalizing the sum of the absolute value of all the model coefficients (Tibshirani 1996). The LASSO objective function is defined as

$$
\min _{\beta}\left(\mathbf{P C P}_{i}-\mathbf{P C X}_{i} \beta\right)^{\mathrm{T}}\left(\mathbf{P C P}_{i}-\mathbf{P C X}_{i} \beta\right)+\lambda \sum_{j=1}^{p}\left|\beta_{j}\right|,
$$

where $j$ refers to the length of column, for $\lambda \geq 0, \lambda$ is computed using a modification of the LARS algorithm of Efron et al. (2004).

Bayesian LASSO regression by Park and Casella (2008) views the LASSO estimate as the mode of the posterior distribution of regression coefficients when the regression parameters have independent and identical Laplace priors. Bayesian LASSO regression mode 1 provides interval estimates (Bayesian credible intervals) that can guide variable selection. In the Bayesian framework, explicit results are available for the posterior probability distributions of the model's parameters when the prior distribution is assumed, and the choice of regularizer is analogous to the choice of prior over the weights (Hans 2009).

After PCPs are regressed by the Bayesian LASSO regression model, we reconstruct the precipitation using the following equation:

$$
\mathbf{P}_{\text {recon }}=\mathbf{P C P} \times \text { Eigenvectors }^{\mathrm{T}}+\mathbf{P}_{m},
$$

where $\mathbf{P}_{\text {recon }}$ is the reconstructed precipitation, Eigenvectors ${ }^{\mathrm{T}}$ is the transposition matrix of PCPs associated spatial eigenvectors, and $\mathbf{P}_{m}$ is the mean precipitation value during the time period (1901-2010) in each grid cell.

\section{d. Forecast models using preseason predictors}

We built five candidate forecast models to explore the preseason predictability. These candidate forecast models differ in the eligible predictors, and the Bayesian LASSO regression method is applied to select predictors in each case. Specifically, PCX is the matrix of standardized regressors and different for the five candidate forecast models:

- Model 1 uses $\mathbf{P C S _ { t - 1 }}$ to forecast $\mathbf{P C P}_{t}$. This is similar to a traditional approach where the current season's SST may be used to predict the following season's precipitation field (Mariotti et al. 2018; Peng et al. 2019; Robertson et al. 2015).

- Model 2 uses $\mathbf{P C l}_{t-1}$ to forecast $\mathbf{P C P}$. The intention was to see if the current PCIs perchance provided a better linear predictor of the future precipitation field than the PCSs.

- Model 3 uses $\mathbf{P} \mathbf{C P}_{t-1}$ to forecast $\mathbf{P C P}_{t}$. This is a simple autoregressive model that we hope is outperformed by the other models considered. 

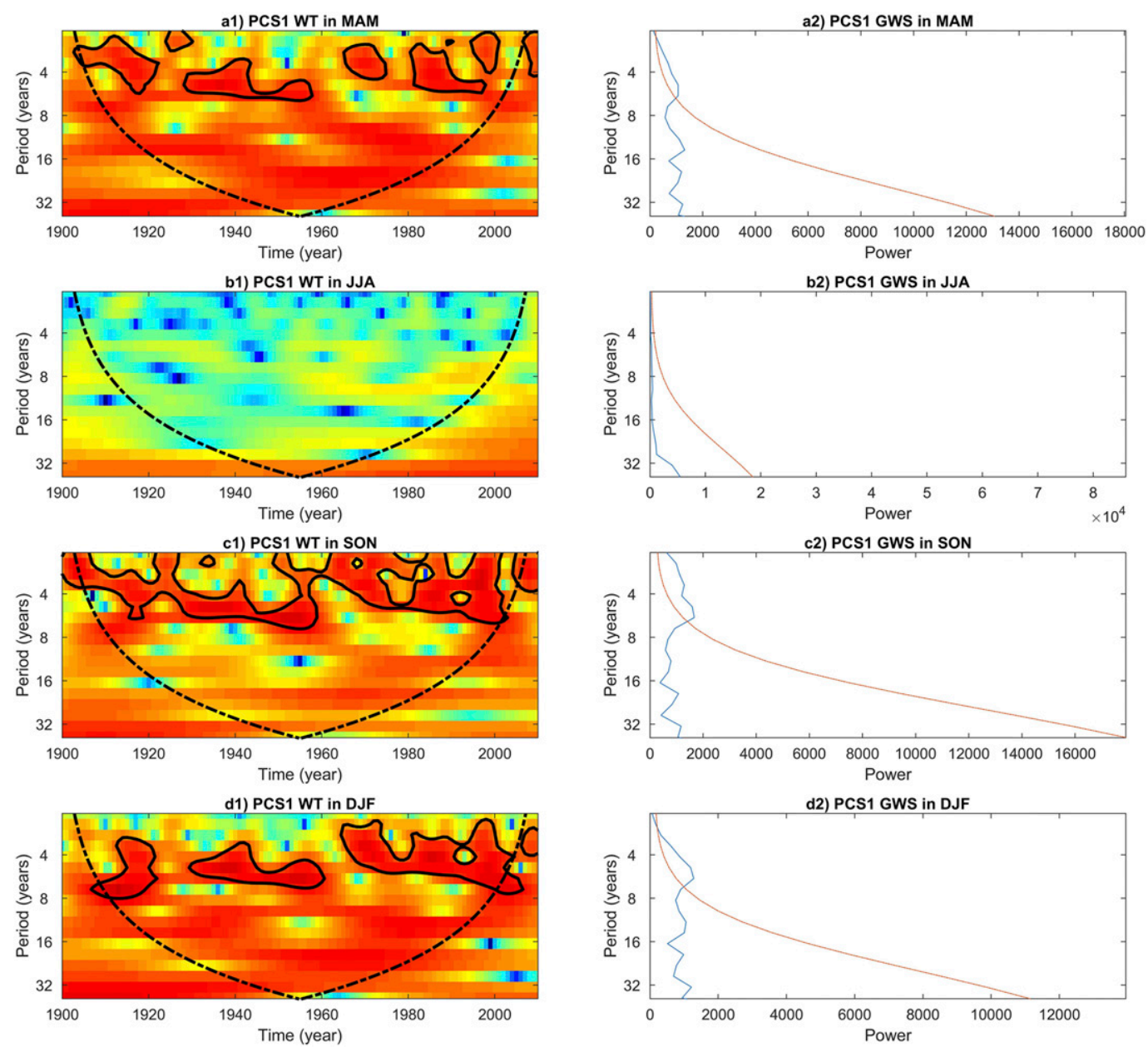

FIG. 2. (left) WT and (right) GWS of the PCS1 time series from 1901 to 2010 for the (a) MAM, (b) JJA, (c) SON, and (d) DJF seasons. The color in WT indicates the wavelet intensity; the black bold contours (WT) and orange lines (GWS) represent the 95\% significance level for a red noise background with lag-1 of 0.72. The cone of influence, representing possible edge effects, is the dash-dotted line in the wavelet power spectrum.

- Model 4 considers $\mathbf{P} \mathbf{C l}_{t-1}, \mathbf{P} \mathbf{C S}_{t-1}, \mathbf{P} \mathbf{C P}_{t-1}$ to forecast $\mathbf{P} \mathbf{C P}_{t}$. By using Bayesian LASSO regression, we hope to find which combination of the current season's state variables translates into the most effective prediction for the next season's precipitation.

- Model 5 uses $\mathbf{P C S}{ }_{t-1}$ to forecast $\mathbf{P C l}$, and then uses $\mathbf{P C l}$ to forecast $\mathbf{P} \mathbf{C P}_{t}$. Here we consider the possibility that predicting the next season's $\mathbf{P C l}$ and then using the concurrent relationship between it and the precipitation provides a better linear predictor than the other choices.

In each case, $\boldsymbol{\beta}$ is a $n \times n$ column vector and represents regression parameters, and $\boldsymbol{\varepsilon}$ is an $k \times n$ column vector and represents independent and identically distributed errors, where $i$ is the number of regressors used in a particular model.

The $K$-fold cross validation is used to test the performance of the regression model that is selected by the LASSO regression (Ly et al. 2013; Räty et al. 2014). The parameter $K$ refers to the number of groups that a given data sample is to be split into, which is chosen as 10 in this paper. The method is summarized as 1) divide the original data into 10 roughly equal groups; 2) take one single group out as the test dataset for each unique group while the remaining groups are the train dataset; 3) fit a model on the training set and evaluate it on the test set; 4) retain the evaluation score and choose the model with the best performance averaged over all the 10 test datasets.

Forecasted precipitation is obtained using Eq. (7) by substituting the best performance forecasted PCPs. Compared with the reconstruction model, it is different in the predictors but the regression methods are the same.

\section{Results}

a. Time evolution and spatial patterns of the PCPs, PCIs, and PCSs

The first 10 PCs of the precipitation field collectively account for $58 \%, 49 \%, 44 \%$, and $56 \%$ of the variability for the MAM, 

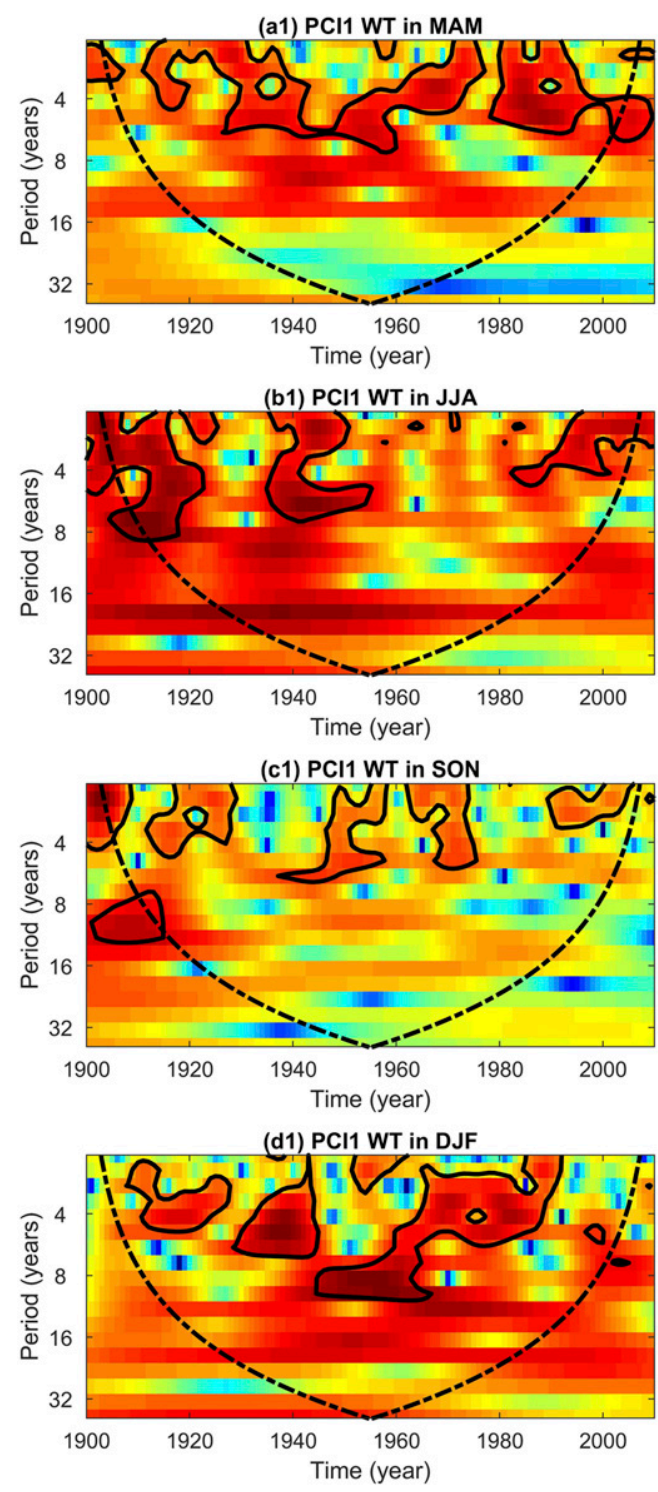

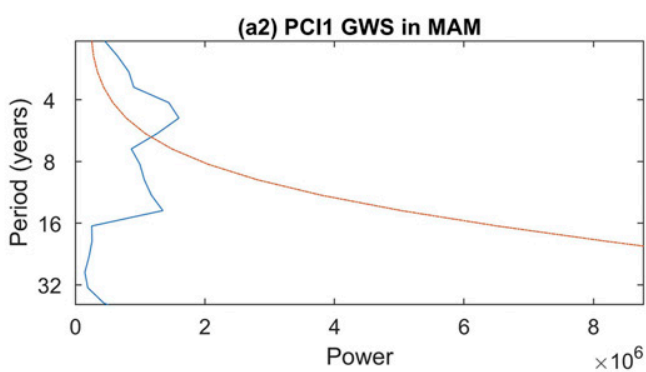

(b2) PCl1 GWS in JJA

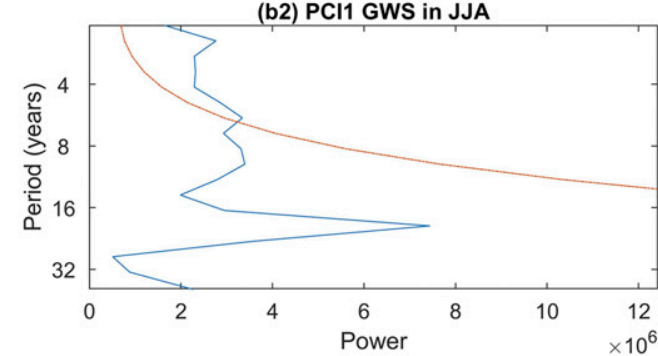

(c2) PCI1 GWS in SON

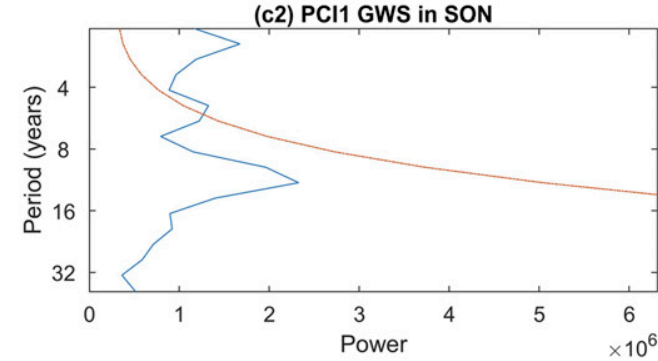

(d2) PCl1 GWS in DJF

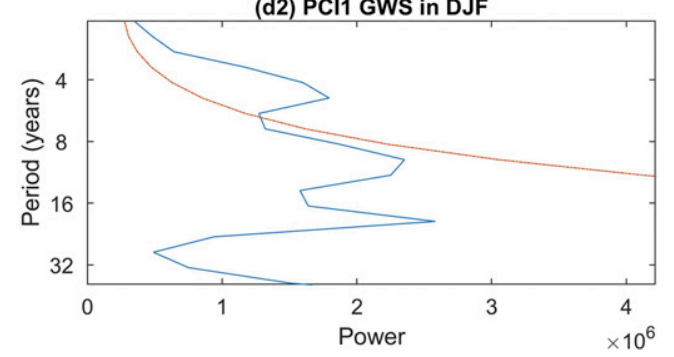

FIG. 3. (left) WT and (right) GWS of the PCI1 time series from 1901 to 2010 for the (a) MAM, (b) JJA, (c) SON, and (d) DJF seasons. The color in WT indicates the wavelet intensity; the black bold contours (WT) and orange lines (GWS) represent the $95 \%$ significance level for a red noise background with lag-1 of 0.72 . The cone of influence, representing possible edge effects, is the dash-dotted line in the wavelet power spectrum.

JJA, SON, and DJF seasons, respectively. Correspondingly, the first 10 PCs collectively account for $58 \%, 60 \%, 56 \%$, and $60 \%$ of the total variability in the IVT for the four seasons. Finally, the first 10 PCs of the SST fields account for $66 \%, 64 \%$, $67 \%$, and $69 \%$ of the total variability for the four seasons. For all the fields, the eleventh and subsequent PCs add less than $2 \%$ of the variance per PC, and this led to our admittedly subjective choice of a stopping criteria for the number of PCs to retain for the analysis. As a result, $k$ is chosen as 10 in this paper, PC's dimension is $10 \times 110$, the total dimension of the gridded field is $360 \times 76 \times 110$. Significant correlation coefficients between PCPs and PCIs, PCSs in the Northern
Hemisphere are calculated to find their connections, as shown in Tables S1-S3 in the online supplemental material. With reference to Tables S1-S3, PCPs and PCIs have larger correlation coefficients than PCPs and PCSs or PCIs and PCSs. To further investigate their teleconnections, wavelet analysis and wavelet coherence were performed on the all PCSs, PCIs, and PCPs to explore their frequency and coherence. The wavelet analysis highlights the dominant scales of temporal variability.

We find statistically significant interannual variability in the 2-8-yr frequency band in the GWS for the leading PCPs, PCIs, and PCSs. Among the four seasons, the MAM season has 

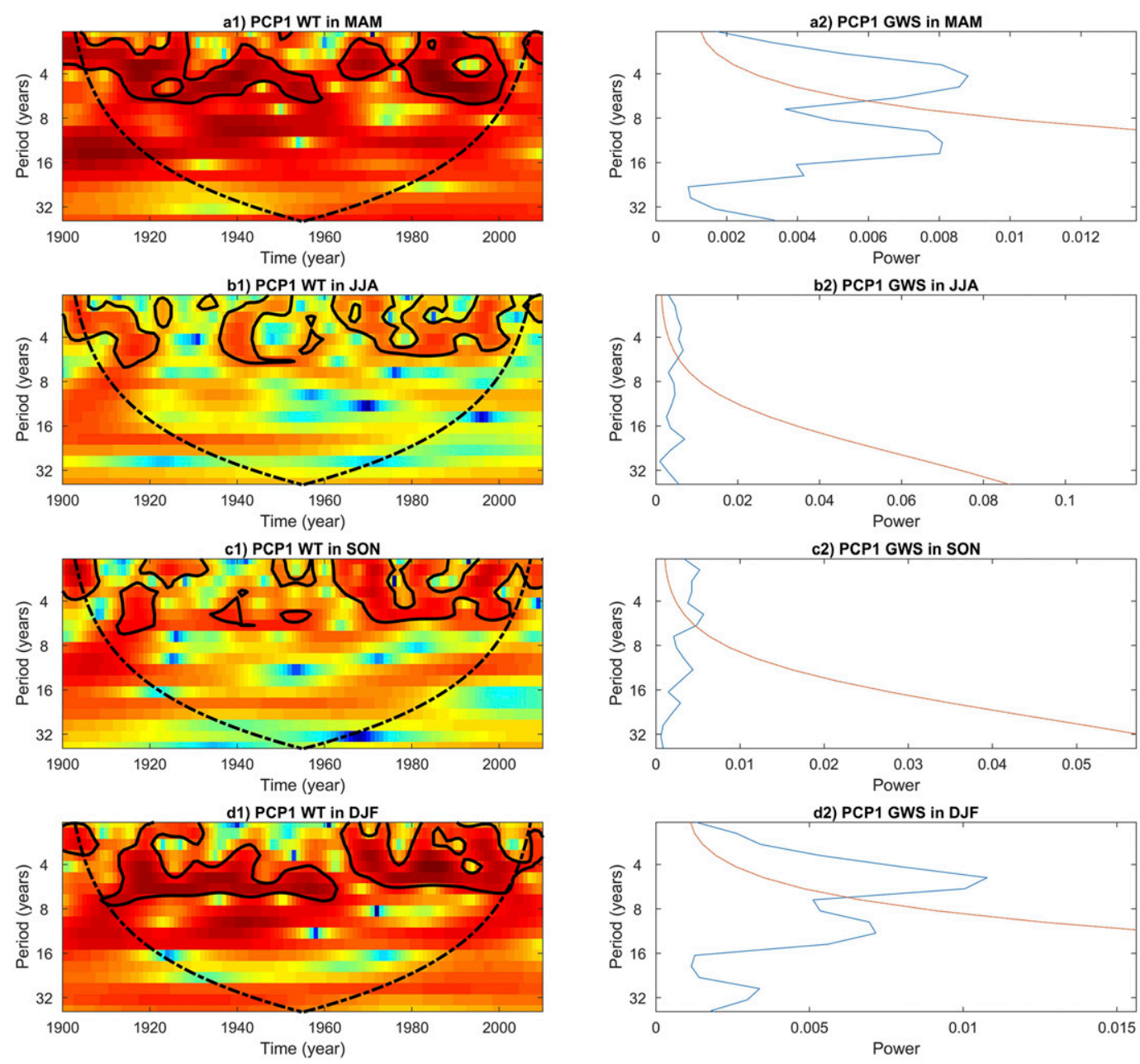

FIG. 4. (left) WT and (right) GWS of the PCP1 time series from 1901 to 2010 for the (a) MAM, (b) JJA, (c) SON, and (d) DJF seasons. The color in WT indicates the wavelet intensity; the black bold contours (WT) and orange lines (GWS) represent the $95 \%$ significance level for a red noise background with lag-1 of 0.72 . The cone of influence, representing possible edge effects, is the dash-dotted line in the wavelet power spectrum.

highest precipitation variance explained for the 2-8-yr frequency band, which is common to the SST and IVT and precipitation fields.

As an example, we illustrate the patterns for PCP1, PCI1, and PCS1, noting that PCP1 is strongly correlated with PCI1 and PCS1. The WT and GWS figures of PCS1, PCI1, and PCP1 in four seasons are demonstrated in Figs. 2-4; the WT and GWS figures of other PCs are shown in the Figs. S1-S27. From these figures, we note that with the exception of JJA where PCS1 does not have a significant variability in the 2-8-yr frequency band, all the variables exhibit a GWS with significant variability in this band.

The question whether this variability is coherent across the precipitation PC and its putative SST and IVT predictors is explored in Fig. 5 through the wavelet coherence between PCS1 and PCI1, PCS1 and PCP1, and PCP1 and PCI1. Apparently, during the time period 1901 to 2010, PCS1 and
PCI1 are remarkably in phase (the right direction of arrow) wavelet coherences for 2-16-yr band almost the whole time period (1901-2010) in MAM, JJA, and SON seasons, while their coherences tend to be antiphase in DJF season. Among the four seasons, the wavelet coherences between PCS1 and PCI1 in MAM are more significant than for the other three seasons.

The synchronous interannual variability across the SST, IVT, and precipitation PCs (please see Figs. S1-S27 in the supplemental material for the details of the lower-order PCs) suggests that even a linear model may do reasonably well to explore associations between the seasonal values of these variables.

According to the ENSO years and intensities based on oceanic Niño index (ONI) (https://ggweather.com/enso/ oni.htm), ENSO was moderate from 1950 to 1955 and from 2002 to 2003, and strong from 1957 to 1958 and from 1965 to 


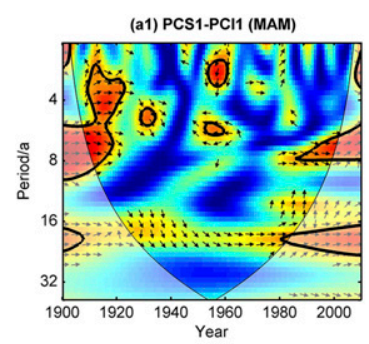

(b1) PCS1-PCP1 (MAM)
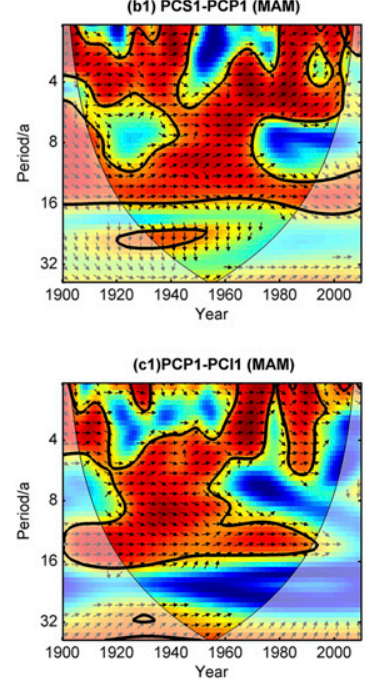

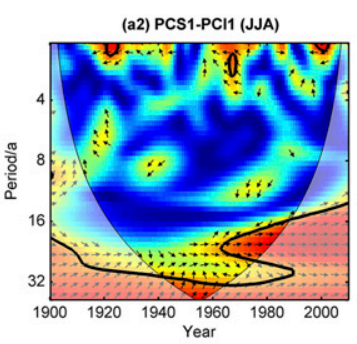

(b2) PCS1-PCP1 (JJA)
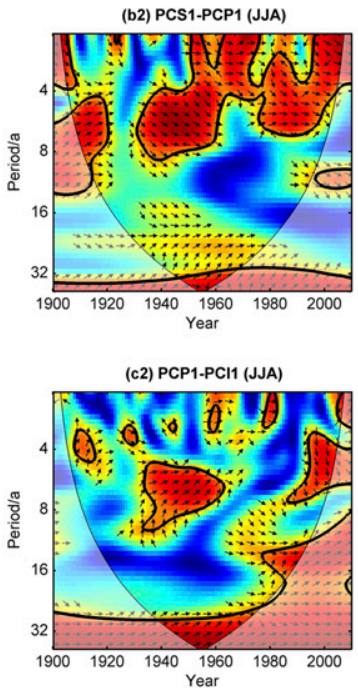

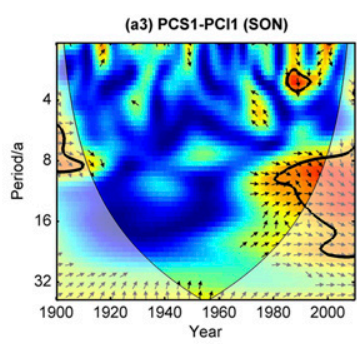

(b3) PCS1-PCP1 (SON)
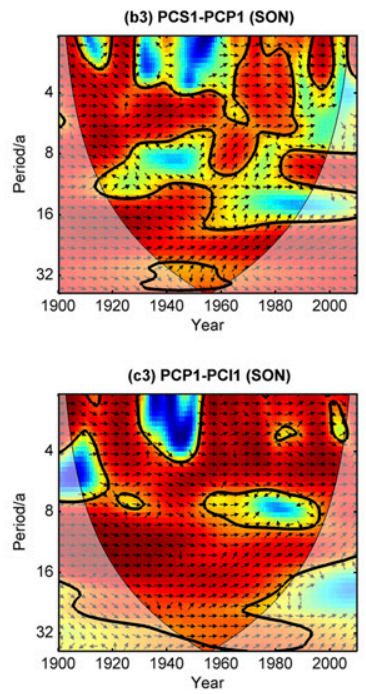

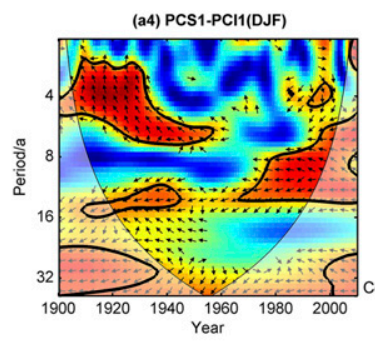

(b4) PCS1-PCP1 (DJF)

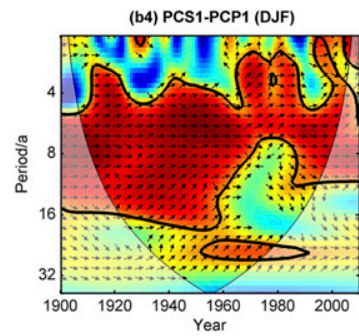

(c4) PCP1-PCI1 (DJF)

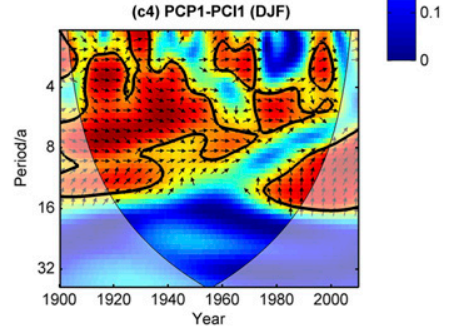

FIG. 5. WTC between the (a) PCS1 and PCI1, (b) PCS1 and PCP1, and (c) PCP1 and PCI1 for the four seasons MAM, JJA, SON, and DJF (in columns from left to right). The thick black contours enclose periods of statistically significant coherence at the $5 \%$ level of a red noise process, and the cone of influence where edge effects might distort the picture is shown as a lighter shade. The phase with right-pointing arrows indicates that the two signals are in phase while left-pointing arrows are for antiphase signals. The colored shading represents the magnitude in the coherence as shown in the right color bar, which varies from 0 to 1 . The value of 1 indicates a perfect correlation in the time-frequency domain, whereas a near-zero coherence value meant no correlation between both time series.

1966, and very strong from 1982 to 1983 and from 1997 to 1998 in the MAM season. During these time periods, there are floods influence by ENSO across many regions, such as the Great Mississippi and Missouri Rivers Flood of 1993. The wavelet spectra for MAM are qualitatively consistent in their amplitude in the interannual frequency band for roughly these time periods. Similar correspondences exist for the other seasons.

In summary, the wavelet analyses and ENSO climatology analyses suggest that precipitation patterns are associated with the tropical dynamics associated with ENSO (Fisman et al. 2016; Kamae et al. 2017). The leading modes identified exhibit interannual variations at time scales and over epochs in the twentieth century that are consistent with those identified by other authors with known low-frequency climate modes.

For brevity, the spatial patterns of the first PC for each field are provided in Figs. 6-8. The others are included in the Figs. S28-S39 in supporting information. The spatial patterns of PCP1 presented in Fig. 8 shows a shifted variation from MAM to DJF, indicating the precipitation in the $\mathrm{NH}$ has substantial seasonality. For different seasons, PCP1 has larger variance in MAM than JJA, SON, and DJF; for geophysical locations, PCP1 has intense variance in southern areas than northern areas in the NH. Figure 6 exhibits that PCS1 has large variance in MAM and SON, DJF, while less variance in JJA, indicating seasonality are existed in IVT. The differences in variance between northern areas and southern areas are also found in PCI1. Figure 7 plots spatial patterns of PCI1 in four seasons and demonstrates that PCI1 has intense variance in MAM, JJA, and SON. Note that PCP1, PCI1, and PCS1 are in agreement of large variance in MAM, which means that connections exist in seasonality for precipitation, IVT, and SST.

Figures 6-8 demonstrate PCS1, PCI1, and PCP1's spatial variance patterns show intensive variation over the tropical eastern Pacific Ocean, consistent with their strong relationships with ENSO. This supports the notion that large-scale SST influence on IVT translates into an influence on precipitation.

\section{b. Reconstruct seasonal precipitation PCs using the concurrent PCs}

We were interested in how well 1) the 10 leading PCPs could reconstruct the seasonal precipitation fields for the Northern 

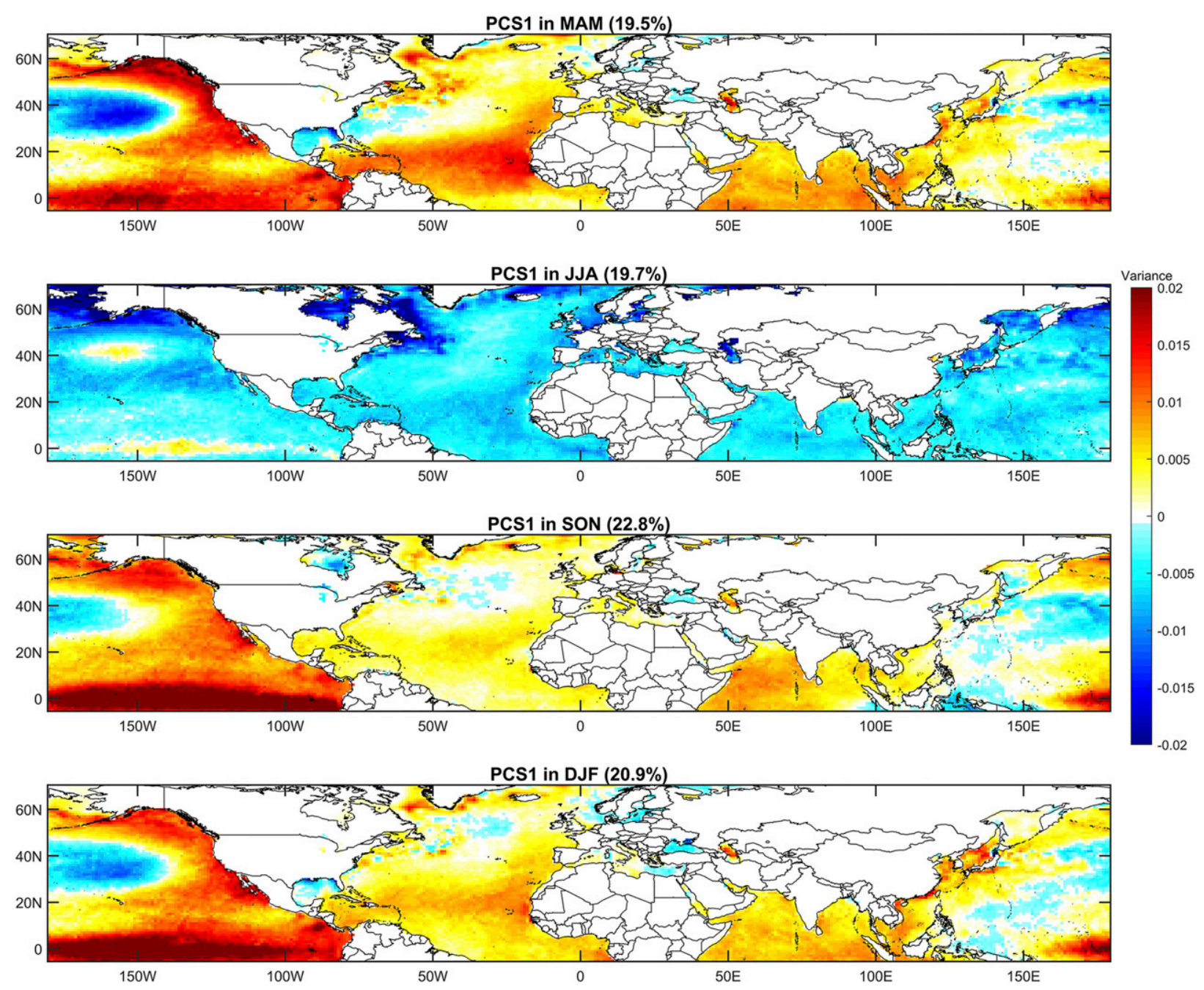

FIG. 6. Spatial patterns of the PCS1 calculated for the 1901-2010 period in four seasons: MAM, JJA, SON, and DJF (shown from top to bottom, respectively). The map colors represent the variance values as shown in the right color bar, and percentages of variance explained by PCS1 are in parentheses.

Hemisphere and 2) the 10 leading PCPs could be reconstructed using the 10 leading PCIs or the 10 leading PCSs. Together, these two questions could inform how well the leading PCIs and PCSs can inform the hemispheric seasonal precipitation field for the same season. The question here is whether as an intermediate causal variable the PCIs add information content beyond what is contained in the seasonal PCSs.

The reconstruction procedure can be summarized as 1) use Bayesian LASSO regression for the 10 leading PCPs to choose the best subset of the 10 leading PCIs and the 10 leading PCSs for the same season; 2) project the predicted PCPs on to the hemisphere using the appropriate part of the original eigenvector matrix used to derive the PCPs; and 3) compare the raw seasonal precipitation maps from the CERA-20C dataset with the seasonal rainfall field generated by reconstructing just the 10 leading PCPs, and then from the 10 leading PCPs as reconstructed from (i) the candidate set of 10 leading PCIs and (ii) from the candidate set of 10 leading PCSs. LASSO typically chooses 4-9 of the candidate PCIs and PCSs to reconstruct concurrent PCPs. This was done for each year and for the average performance across years. Here, we illustrate the reconstruction for the time period from 1901 to 2010 in Fig. S40: original precipitation map, absolute difference between PCP reconstructed and actual precipitation maps, absolute difference between PCI reconstructed and actual precipitation maps, absolute difference between PCS reconstructed, and actual precipitation maps in JJA are listed from top to bottom.

PCP reconstructed precipitation maps maintain the main characteristics of the original precipitation maps, the absolute differences in all grids are less than $0.05 \mathrm{~mm}^{\text {day }}{ }^{-1}$ in the $\mathrm{NH}$ during the whole time period from 1901 to 2010. PCI reconstructed precipitation maps reproduce the main characteristics of PCP reconstructed precipitation maps. There were no significant differences between PCI reconstructed precipitation and original precipitation maps. The 10 leading PCPs are 

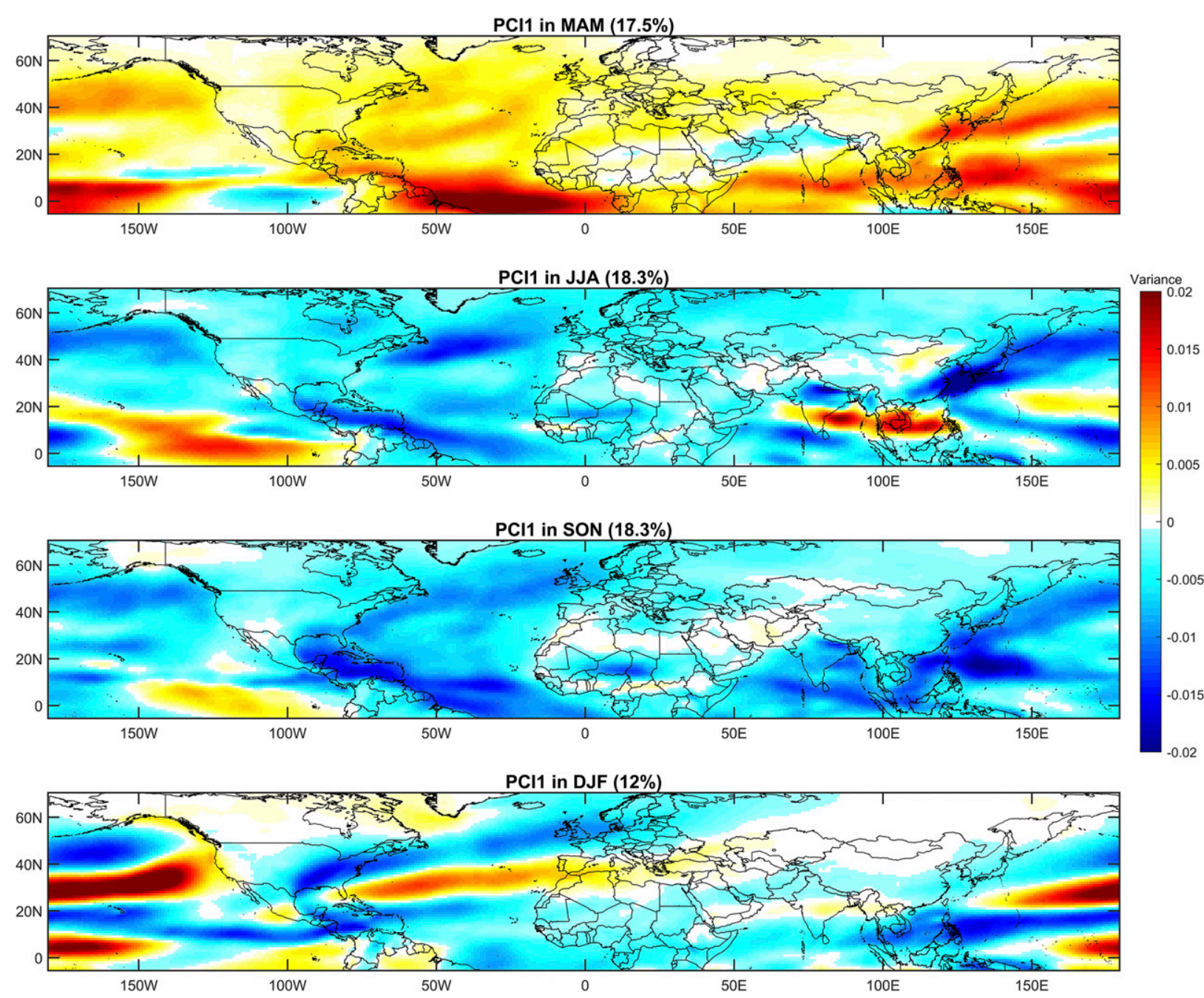

FIG. 7. Spatial patterns of the PCI1 calculated for the 1901-2010 period in four seasons: MAM, JJA, SON, and DJF (shown from top to bottom, respectively). The map colors represent the variance values as shown in the right color bar, and percentages of variance explained by PCI1 are in parentheses.

reconstructed separately and then the coefficient of determination $\left(R^{2}\right)$ is calculated for each PCP; as a result, the $R^{2}$ in multiple linear regression models' values range from 0.32 to 0.91 (10 PCPs have 10 coefficients of determination) for MAM, from 0.27 to 0.8 for JJA, from 0.22 to 0.78 for SON, and from 0.25 to 0.84 for DJF during the time period from 1901 to 2010 . The absolute mean differences between PCI reconstructed and actual precipitation data in grids during the time period from 1901 to 2010 are less than $0.15 \mathrm{~mm}$ day $^{-1}$. Compared with PCI reconstructed maps, PCS reconstructed precipitation maps reproduce the main characteristics of PCP reconstructed precipitation maps but are not as informative, suggesting that the PCIs contain a bit more directly relevant information.

As the differences between reconstructed and actual precipitation data may be hidden by mean value calculations, we choose the reconstruction in year 2000 in Fig. 9 as an example. For PCI reconstructed precipitation data, for the individual grid points the relative reconstruction error (error variance divided by data variance) varies between $2 \%$ and $23 \%$ for MAM, JJA, SON, and DJF seasons in 2000. The spatial correlation coefficients between observed precipitation and PCI reconstructed precipitation across the map are 0.95, 0.96, 0.93 , and 0.95 separately for MAM, JJA, SON, and DJF seasons in the year 2000.

For PCS reconstructed precipitation, at the individual grid points the relative reconstruction error (error variance divided by data variance) varies between $4 \%$ and $36 \%$ for MAM, JJA, SON, and DJF seasons in 2000. The coefficient of determination in multiple linear regression models' values range from 0.2 to 0.88 for MAM, from 0.15 to 0.81 for JJA, from 0.17 to 0.87 for SON, and from 0.11 to 0.76 for DJF during the time period from 1901 to 2010. The spatial correlation coefficients between observed precipitation and PCS reconstructed precipitation are $0.89,0.95,0.94$, and 0.92 separately for MAM, JJA, SON, and DJF seasons in 2000 year. The PCI and PCS reconstructed precipitation maps are similar to the original 

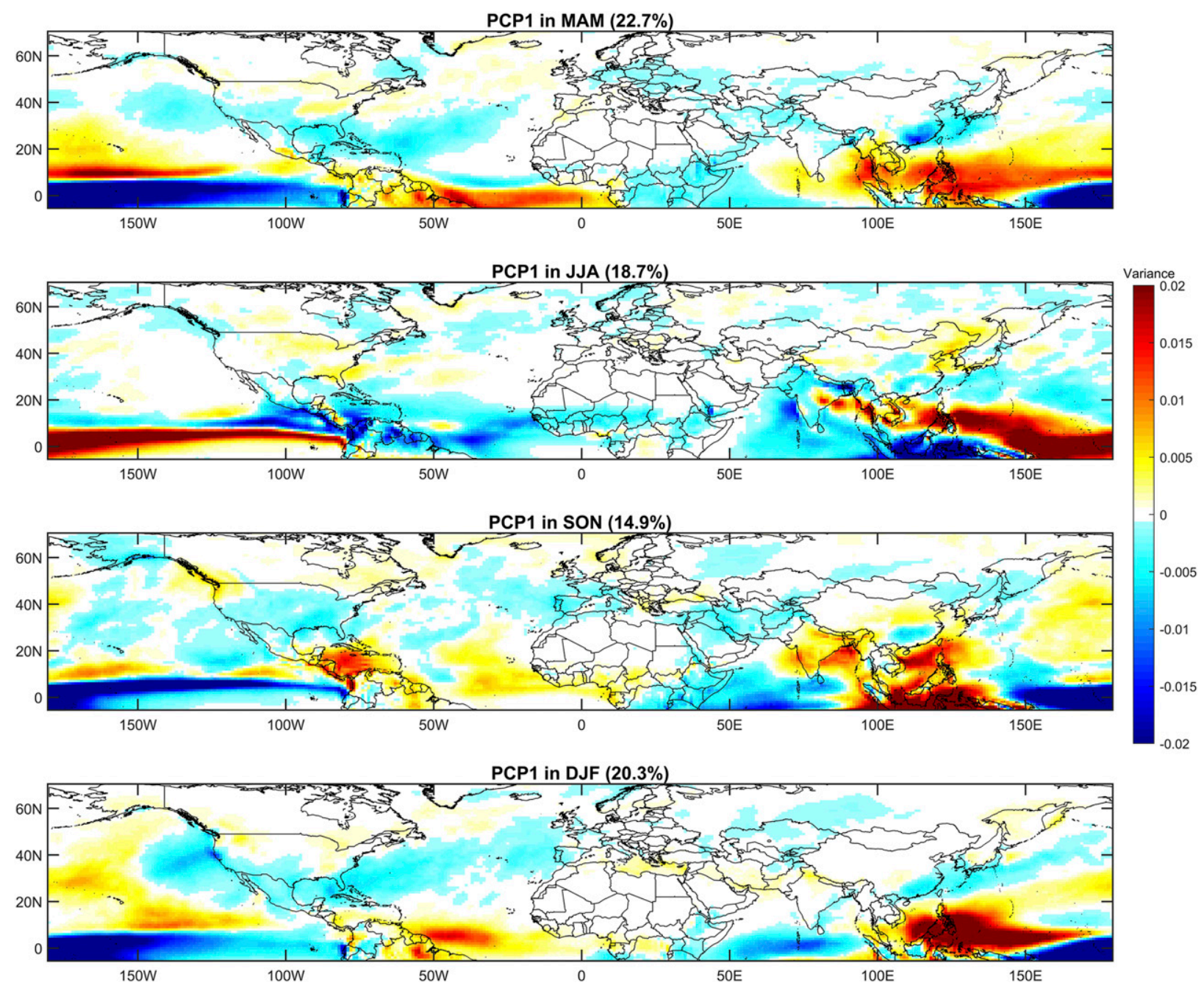

FIG. 8. Spatial patterns of the PCP1 calculated for the 1901-2010 period in four seasons: MAM, JJA, SON, and DJF (shown from top to bottom, respectively). The map colors represent the variance values as shown in the right color bar, and percentages of variance explained by PCP1 are in parentheses.

precipitation maps in JJA except for some inconsistencies in the northeastern Pacific Ocean.

\section{c. Forecast models for the next season}

We considered five distinct models to assess the predictability of a subsequent season's precipitation using the IVT and SST fields. Bayesian LASSO regression is used to choose the best predictors for each case, and the best performing model is selected by $K$-fold cross validation using minimum average root-mean-square error (RMSE) for the 10 PCPs.

\section{1) MOdEl SELECTION AND FORECAST PERFORMANCE}

Each of the 10 PCPs was regressed separately on the candidate predictors for each model. The coefficients of determination for each of the 10 PCPs shown in Table 1 . Model 4 consistently has the best performance among these models. Model 4 aggregates PCPs, PCIs, and PCSs as predictors resulting in stable and better forecast accuracy than the other models. Model 4's predictors chosen by LASSO for each PCP in each season are shown in Table 2. Predictors kept by LASSO correspond to the PCPs that are correlated to PCIs or PCSs, as noted in section $4 \mathrm{a}$, and typically have spatial patterns that make sense for physical teleconnections. Figure S43 shows the posterior frequency distributions of the PCP1 (JJA) predictors' coefficients. It can be seen that the PCIs have the largest contribution rate to the PCP1 from the regression parameters' probability density functions.

\section{2) FORECAST PERFORMANCE}

The raw seasonal precipitation maps using CERA-20C dataset are compared with the model 4 forecasted precipitation maps. This was done for each year and for the average across years. First, we illustrate the forecast precipitation for the time period from 1901 to 2010 in Fig. 10. The maps in the right column are derived in three steps: 1) predict each PCP in 
(1) Original precipitation data in JJA (2000)

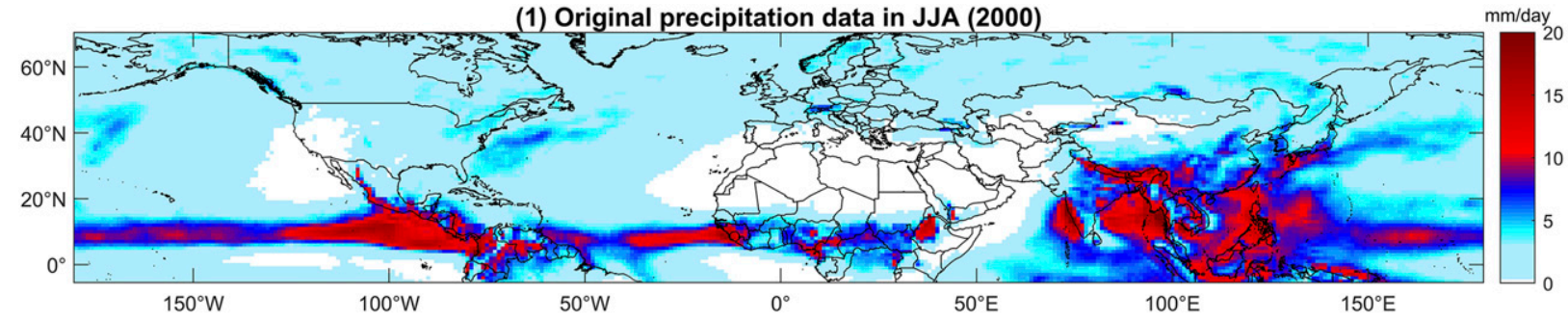

(2) Difference between PCP reconstructed and actual precipitation data in JJA (2000)

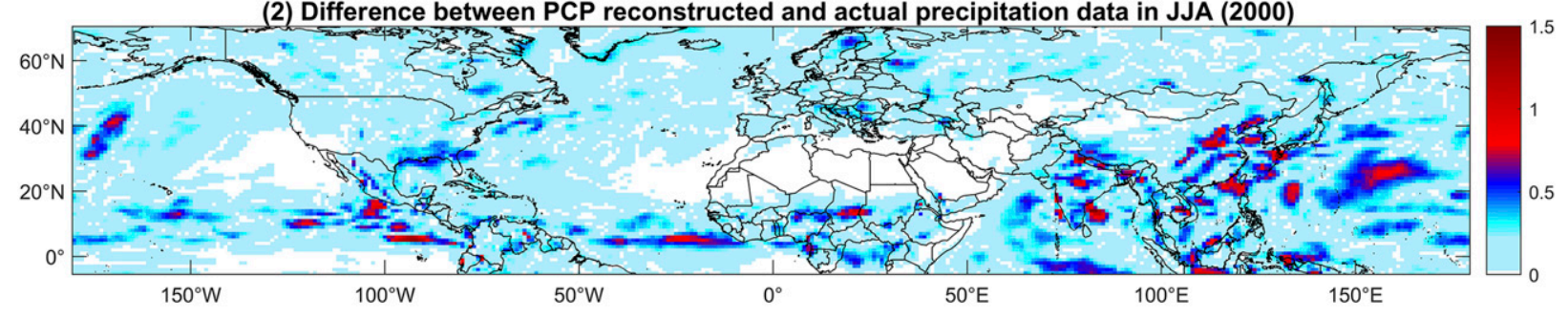

(3) Difference between $\mathrm{PCl}$ reconstructed and actual precipitation data in JJA (2000)

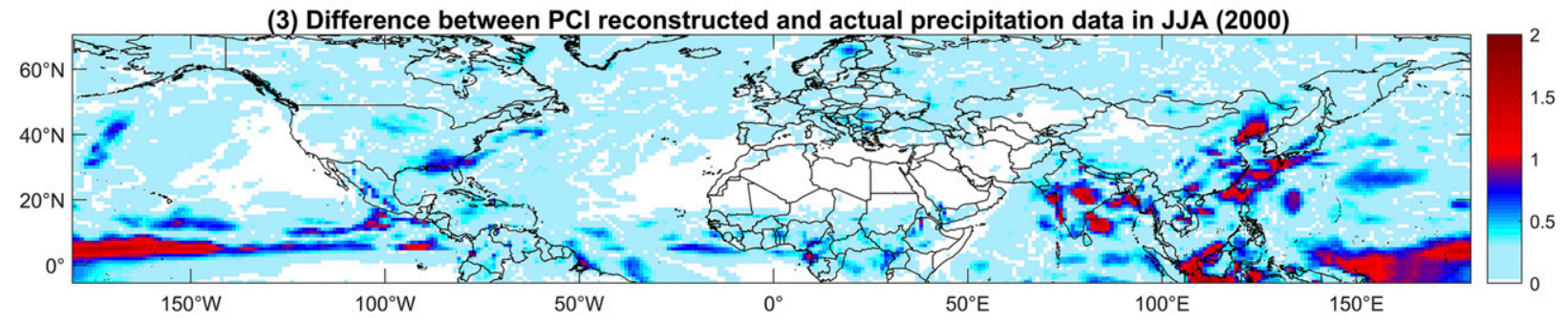

(4) Difference between PCS reconstructed and actual precipitation data in JJA (2000)

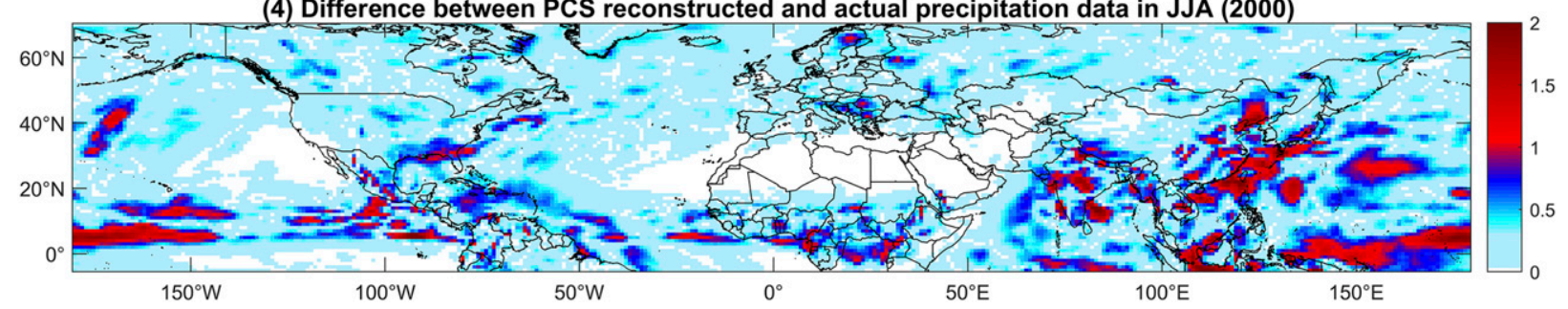

FIG. 9. Comparisons between PCP, PCI, and PCS reconstructed precipitation maps and original precipitation maps in JJA in 2000: 1) original precipitation data using CERA-20C, 2) absolute difference between PCP reconstructed and actual precipitation data, 3) absolute difference between PCI reconstructed and actual precipitation data, and 4) absolute difference between PCS reconstructed and actual precipitation data.

each grid by model 4 ; 2) reconstruct precipitation field by 10 predicted PCPs; and 3) calculate the absolute difference between forecasted precipitation and original precipitation data. The forecast performance is assessed by the values of absolute difference.

Model 4 forecast precipitation maps maintain the main characteristics of original precipitation maps, the absolute differences in all grids are less than $0.2 \mathrm{~mm}$ day $^{-1}$ in the $\mathrm{NH}$ during the whole time period from 1901 to 2010. The absolute differences between forecast and actual precipitation are smaller in JJA than MAM, consistent with the coefficients of determination indicated in Table 1.

The forecast for the year 2000, the original precipitation maps and absolute difference between model 4 forecast and actual precipitation maps in four seasons are displayed in Fig. 11. The forecast models in Figs. 10 and 11 are also based on the Bayesian LASSO regression method, while Fig. 9 is using concurrent predictors to reconstruct the seasonal precipitation. PCP, PCI, and PCS are used to reconstruct seasonal precipitation for the year 2000, comparing with the raw seasonal precipitation maps using CERA-20C dataset. Figures 10 and 11 are using preseason predictors in model 4 to forecast the seasonal precipitation in the next season, and Fig. 10 was done for the average across years while Fig. 11 was for the year 2000 .

The absolute differences of Fig. 11 in all grids are less than $4 \mathrm{~mm} \mathrm{day}^{-1}$ in the NH. For individual grid points the relative forecast error (error variance divided by data variance) varies 
TABLE 1. Forecast models' coefficients of determination in the four seasons. Model 4 is bolded.

\begin{tabular}{lccccccccccc}
\hline \hline Models & Seasons & PCP1 & PCP2 & PCP3 & PCP4 & PCP5 & PCP6 & PCP7 & PCP8 & PCP9 & PCP10 \\
\hline Model 1 & MAM & 0.52 & 0.61 & 0.34 & 0.37 & 0.52 & 0.02 & 0.38 & 0.38 & 0.07 & 0.03 \\
Model 2 & & 0.32 & 0.66 & 0.22 & 0.18 & 0.41 & 0.15 & 0.29 & 0.28 & 0.14 & 0.08 \\
Model 3 & & 0.49 & 0.73 & 0.12 & 0.32 & 0.4 & 0.22 & 0.31 & 0.2 & 0.05 & 0.09 \\
Model 4 & & $\mathbf{0 . 6 5}$ & $\mathbf{0 . 8}$ & $\mathbf{0 . 4 2}$ & $\mathbf{0 . 5}$ & $\mathbf{0 . 6 1}$ & $\mathbf{0 . 3 6}$ & $\mathbf{0 . 4 2}$ & $\mathbf{0 . 5 2}$ & $\mathbf{0 . 2 2}$ & $\mathbf{0 . 1 1}$ \\
Model 5 & & 0.52 & 0.6 & 0.28 & 0.37 & 0.52 & 0.02 & 0.36 & 0.37 & 0.06 & 0.04 \\
Model 1 & JJA & 0.72 & 0.72 & 0.17 & 0.27 & 0.25 & 0.2 & 0.18 & 0.04 & 0.02 & 0.15 \\
Model 2 & & 0.77 & 0.68 & 0.27 & 0.31 & 0.12 & 0.05 & 0.07 & 0.04 & 0.07 & 0.09 \\
Model 3 & & 0.8 & 0.68 & 0.25 & 0.31 & 0.23 & 0.32 & 0.19 & 0.12 & 0.24 \\
Model 4 & & $\mathbf{0 . 8 5}$ & $\mathbf{0 . 8 3}$ & $\mathbf{0 . 3 7}$ & $\mathbf{0 . 4 2}$ & $\mathbf{0 . 3 8}$ & $\mathbf{0 . 4}$ & $\mathbf{0 . 2 9}$ & $\mathbf{0 . 1 5}$ & $\mathbf{0 . 2 1}$ \\
Model 5 & & 0.72 & 0.72 & 0.16 & 0.27 & 0.22 & 0.2 & 0.16 & 0.02 & 0.02 \\
Model 1 & SON & 0.43 & 0.34 & 0.35 & 0.38 & 0.34 & 0.23 & 0.1 & 0.05 & 0.18 \\
Model 2 & & 0.16 & 0.29 & 0.35 & 0.2 & 0.03 & 0.22 & 0.01 & 0.02 & 0.15 \\
Model 3 & & 0.17 & 0.44 & 0.32 & 0.22 & 0.17 & 0.19 & 0.01 & 0.02 & 0.06 \\
Model 4 & & $\mathbf{0 . 4 8}$ & $\mathbf{0 . 5 1}$ & $\mathbf{0 . 4 3}$ & $\mathbf{0 . 4}$ & $\mathbf{0 . 4 6}$ & $\mathbf{0 . 3 3}$ & $\mathbf{0 . 0 5}$ & $\mathbf{0 . 0 6}$ & $\mathbf{0 . 2 1}$ \\
Model 5 & & 0.43 & 0.33 & 0.34 & 0.35 & 0.33 & 0.22 & 0.03 & 0.01 & 0.13 \\
Model 1 & DJF & 0.64 & 0.32 & 0.66 & 0.43 & 0.12 & 0.44 & 0.06 & 0.16 & 0.05 & 0.02 \\
Model 2 & & 0.56 & 0.14 & 0.63 & 0.38 & 0.25 & 0.18 & 0.25 & 0.1 & 0.06 \\
Model 3 & & 0.74 & 0.54 & 0.56 & 0.46 & 0.27 & 0.2 & 0.06 & 0.16 & 0.09 & 0.04 \\
Model 4 & & $\mathbf{0 . 7 7}$ & $\mathbf{0 . 6 1}$ & $\mathbf{0 . 7 7}$ & $\mathbf{0 . 6 3}$ & $\mathbf{0 . 3 1}$ & $\mathbf{0 . 5 5}$ & $\mathbf{0 . 3 1}$ & $\mathbf{0 . 2 4}$ & $\mathbf{0 . 1 1}$ & $\mathbf{0 . 1 2}$ \\
Model 5 & & 0.63 & 0.24 & 0.65 & 0.41 & 0.04 & 0.43 & 0.05 & 0.17 & 0.06 & 0.01 \\
\hline
\end{tabular}

between $5 \%$ and $34 \%$ for MAM, JJA, SON, and DJF seasons for the year 2000. The spatial correlation coefficients between observed precipitation and Model 4 forecasted precipitation are $0.82,0.89,0.83$, and 0.79 separately for MAM, JJA,
SON, and DJF seasons in 2000 year. The spatial correlation coefficients between observed precipitation and model 4 forecasted precipitation for MAM, JJA, SON, and DJF seasons are shown in Fig. S42. Compared with original

TABLE 2. Model 4's predictors kept by LASSO in the four seasons.

\begin{tabular}{|c|c|c|c|c|c|c|c|c|c|c|}
\hline Seasons & PCP1 & PCP2 & PCP3 & PCP4 & PCP5 & РCP6 & PCP7 & РCP8 & РCP9 & PCP10 \\
\hline MAM & $\begin{array}{l}\text { PCI1, } \\
\text { PCI2, } \\
\text { PCI3, } \\
\text { PCS1, } \\
\text { PCS2, } \\
\text { PCS3 }\end{array}$ & $\begin{array}{l}\text { PCI2, } \\
\text { PCI3, } \\
\text { PCI4, } \\
\text { PCS5, } \\
\text { PCS6 }\end{array}$ & $\begin{array}{l}\text { PCI1, } \\
\text { PCI3, } \\
\text { PCI5, } \\
\text { PCS1, } \\
\text { PCS2 }\end{array}$ & $\begin{array}{l}\text { PCI1, } \\
\text { PCI2, } \\
\text { PCI3, } \\
\text { PCI4, } \\
\text { PCS5, } \\
\text { PCS6, } \\
\text { PCS8 }\end{array}$ & $\begin{array}{l}\text { PCI1, } \\
\text { PCI4, } \\
\text { PCI5, } \\
\text { PCI6, } \\
\text { PCS6, } \\
\text { PCS8, } \\
\text { PCS10 }\end{array}$ & $\begin{array}{l}\text { PCI2, } \\
\text { PCI6, } \\
\text { PCI7, } \\
\text { PCS3, } \\
\text { PCS4 }\end{array}$ & $\begin{array}{l}\text { PCI6, } \\
\text { PCI7, } \\
\text { PCI8, } \\
\text { PCS5, } \\
\text { PCS7 }\end{array}$ & $\begin{array}{l}\text { PCI5, } \\
\text { PCI7, } \\
\text { PCI8, } \\
\text { PCS4, } \\
\text { PCS9, } \\
\text { PCS10 }\end{array}$ & $\begin{array}{l}\text { PCI5, } \\
\text { PCI6, } \\
\text { PCI9, } \\
\text { PCS5, } \\
\text { PCS8 }\end{array}$ & $\begin{array}{l}\text { PCI6, } \\
\text { PCI8, } \\
\text { PCS6 }\end{array}$ \\
\hline JJA & $\begin{array}{l}\text { PCI1, } \\
\text { PCI3, } \\
\text { PCS1, } \\
\text { PCS2 }\end{array}$ & $\begin{array}{l}\text { PCI1, } \\
\text { PCI2, } \\
\text { PCI4, } \\
\text { PCI5, } \\
\text { PCS1, } \\
\text { PCS2, } \\
\text { PCS5 }\end{array}$ & $\begin{array}{l}\text { PCI2, } \\
\text { PCI4, } \\
\text { PCI7, } \\
\text { PCS2, } \\
\text { PCS3, } \\
\text { PCS8 }\end{array}$ & $\begin{array}{l}\text { PCI2, } \\
\text { PCI6, } \\
\text { PCS1, } \\
\text { PCS4, } \\
\text { PCS7 }\end{array}$ & $\begin{array}{l}\text { PCI3, } \\
\text { PCI5, } \\
\text { PCI7, } \\
\text { PCS3, } \\
\text { PCS6, } \\
\text { PCS8 }\end{array}$ & $\begin{array}{l}\text { PCI6, } \\
\text { PCI8, } \\
\text { PCS3, } \\
\text { PCS7 }\end{array}$ & $\begin{array}{l}\text { PCI2, } \\
\text { PCI4, } \\
\text { PCS7 }\end{array}$ & $\begin{array}{l}\text { PCI1, } \\
\text { PCI4, } \\
\text { PCI6, } \\
\text { PCS5, } \\
\text { PCS7, } \\
\text { PCS8 }\end{array}$ & $\begin{array}{l}\text { PCI4, } \\
\text { PCI7, } \\
\text { PCS6, } \\
\text { PCS9 }\end{array}$ & $\begin{array}{l}\text { PCI7, } \\
\text { PCS1, } \\
\text { PCS3, } \\
\text { PCS5 }\end{array}$ \\
\hline SON & $\begin{array}{l}\text { PCI1, } \\
\text { PCI2, } \\
\text { PCI3, } \\
\text { PCS1, } \\
\text { PCS2 }\end{array}$ & $\begin{array}{l}\text { PCI1, } \\
\text { PCI3, } \\
\text { PCS1, } \\
\text { PCS5, } \\
\text { PCS9 }\end{array}$ & $\begin{array}{l}\text { PCI1, } \\
\text { PCI2, } \\
\text { PCI3, } \\
\text { PCI4, } \\
\text { PCS2, } \\
\text { PCS3 }\end{array}$ & $\begin{array}{l}\text { PCI2, } \\
\text { PCI4, } \\
\text { PCI7, } \\
\text { PCS2, } \\
\text { PCS3, } \\
\text { PCS7 }\end{array}$ & $\begin{array}{l}\text { PCI4, } \\
\text { PCI5, } \\
\text { PCS3, } \\
\text { PCS7 }\end{array}$ & $\begin{array}{l}\text { PCI2, } \\
\text { PCI10, } \\
\text { PCS6 }\end{array}$ & $\begin{array}{l}\text { PCI4, } \\
\text { PCI6, } \\
\text { PCI8, } \\
\text { PCS3, } \\
\text { PCS5 }\end{array}$ & $\begin{array}{l}\text { PCI5, } \\
\text { PCI7, } \\
\text { PCS6, } \\
\text { PCS7, } \\
\text { PCS9 }\end{array}$ & $\begin{array}{l}\text { PCI9, } \\
\text { PCS9 }\end{array}$ & $\begin{array}{l}\text { PCI5, } \\
\text { PCI6, } \\
\text { PCS6, } \\
\text { PCS7, } \\
\text { PCS10 }\end{array}$ \\
\hline DJF & $\begin{array}{l}\text { PCI1, } \\
\text { PCI2, } \\
\text { PCI3, } \\
\text { PCI5, } \\
\text { PCS1, } \\
\text { PCS2, } \\
\text { PCS3 }\end{array}$ & $\begin{array}{l}\text { PCI3, } \\
\text { PCI4, } \\
\text { PCI7, } \\
\text { PCS2, } \\
\text { PCS7, } \\
\text { PCS8 }\end{array}$ & $\begin{array}{l}\text { PCI1, } \\
\text { PCI2, } \\
\text { PCI3, } \\
\text { PCS1, } \\
\text { PCS2, } \\
\text { PCS3 }\end{array}$ & $\begin{array}{l}\text { PCI1, } \\
\text { PCI2, } \\
\text { PCI3, } \\
\text { PCS1, } \\
\text { PCS3, } \\
\text { PCS7 }\end{array}$ & $\begin{array}{l}\text { PCI1, } \\
\text { PCI2, } \\
\text { PCI3, } \\
\text { PCI5, } \\
\text { PCS4 }\end{array}$ & $\begin{array}{l}\text { PCI2, } \\
\text { PCI3, } \\
\text { PCI4, } \\
\text { PCS1, } \\
\text { PCS5 }\end{array}$ & $\begin{array}{l}\text { PCI5, } \\
\text { PCI7, } \\
\text { PCI8, } \\
\text { PCS4, } \\
\text { PCS6 }\end{array}$ & $\begin{array}{l}\text { PCI5, } \\
\text { PCI7, } \\
\text { PCS8 }\end{array}$ & $\begin{array}{l}\text { PCI7, } \\
\text { PCI9, } \\
\text { PCS6, } \\
\text { PCS9 }\end{array}$ & $\begin{array}{l}\text { PCI6, } \\
\text { PCI9, } \\
\text { PCS2, } \\
\text { PCS6 }\end{array}$ \\
\hline
\end{tabular}



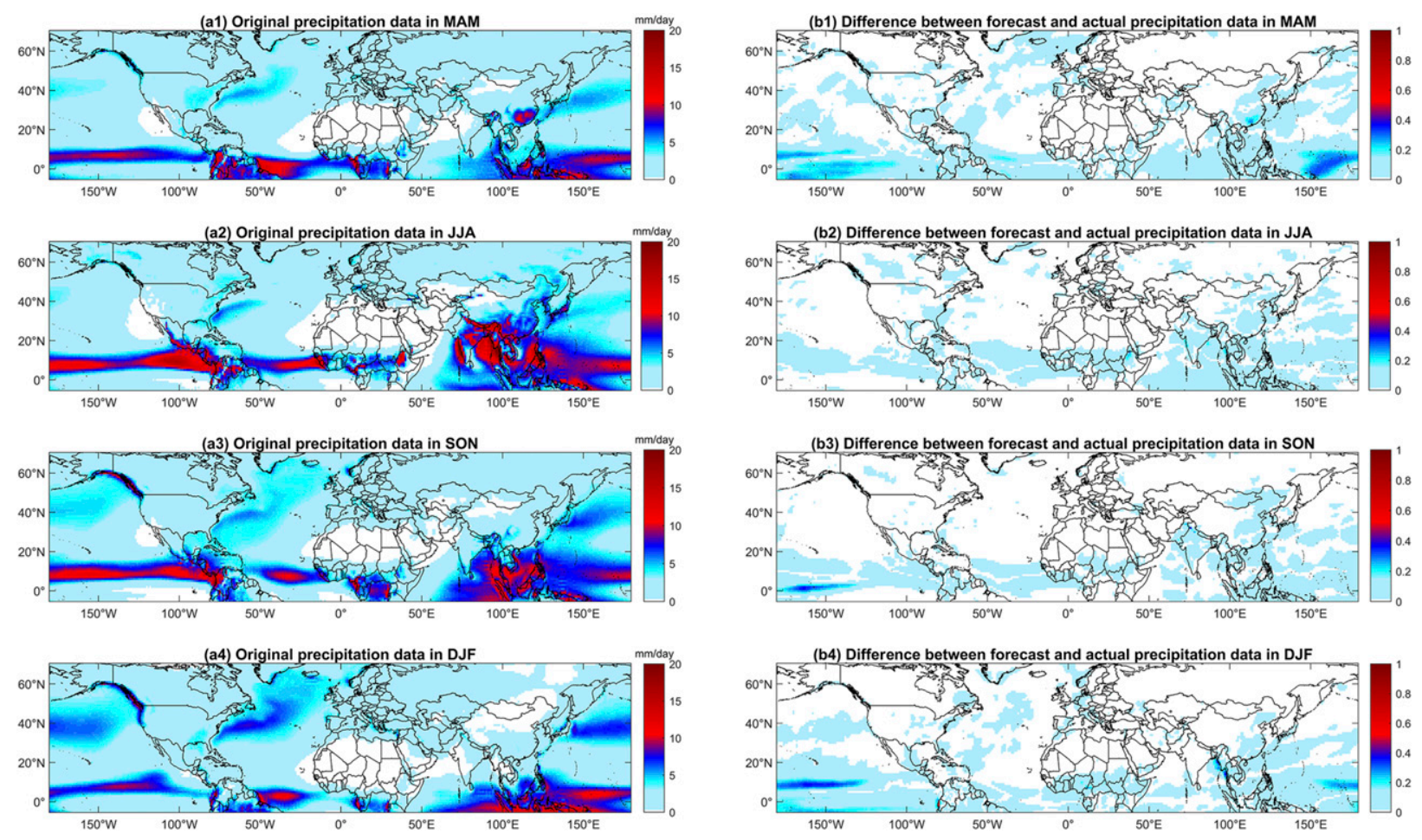

FIG. 10. Comparisons between model 4 forecast precipitation maps and original precipitation maps during the time period from 1901 to 2010 : (a1)-(a4) original precipitation data using CERA-20C in the MAM, JJA, SON, and DJF seasons and (b1)-(b4) absolute differences between forecast and actual precipitation in the MAM, JJA, SON, and DJF seasons. Annual data are mean value for each year using daily precipitation.

precipitation data, model 4 forecasted precipitation data reveal small variance in areas around $40^{\circ} \mathrm{N}$ and tropical Atlantic Ocean in MAM and DJF, large variance in North Pacific Ocean in JJA and SON.

\section{Summary and discussion}

The work presented here was motivated by a desire to understand the importance of large-scale atmospheric circulation and the associated water vapor transport and sea surface temperature in determining hemispheric precipitation at interannual and longer time scales. In this context, we considered spatiotemporal organization in hemispheric precipitation and IVT and SST for each season, using the CERA-20C datasets. The leading principal components of the precipitation and the IVT and SST fields illustrated complementary spatial and temporal structure for each season, suggesting that the leading modes of seasonal precipitation and IVT and SST may be coherent. Indeed, this is confirmed by both the wavelet coherence and the spatial correlation analyses. The next questions were whether a reconstruction of the hemispheric precipitation fields by the leading precipitation principal components, and of those PCs by the PCs of IVT and SST that are most associated with each of the precipitation PCs, can provide a reconstruction of the observed precipitation fields. The answer to both questions is in the affirmative, based on regression and field reconstruction using a relatively small number of components, at the hemispheric as well as at the individual grid box level, across years and for specific years. The interannual variability of the three fields also shows coherent variations, especially in the 2-8-yr frequency band that is usually associated with tropical climate variability.

The skill in the reconstructions and the forecasts is largely in the equatorial and tropical regions, which are typically marked by higher precipitation and higher precipitation variability. This is interesting since the skill of season-ahead forecasts using general circulation models is also typically higher in these regions than in the extratropics. (https://iri.columbia.edu/ourexpertise/climate/forecasts/verification/). We plan to explore a different design for the investigation of the IVT extratropical relationships, including the stability of those relations over time, considering the global warming trend.

We explored the development of a season-ahead forecasting model for hemispheric precipitation fields using IVTs and SSTs derived from CERA-20C. The current work explored the utility and application to seasonal to decadal forecasting of precipitation, if the IVTs are modeled better than precipitation by numerical models of future climate. It also provides diagnostics for the evaluation of the relative importance of temperature scaling versus circulation for precipitation changes. We recognize that all these analyses are in the context of a single climate reanalysis dataset, and not for observed precipitation or accounting for the uncertainty across models. Our purpose here was to explore whether or not large-scale circulation patterns as embedded in the IVT or SST, could indeed provide a meaningful surrogate for seasonal precipitation at 

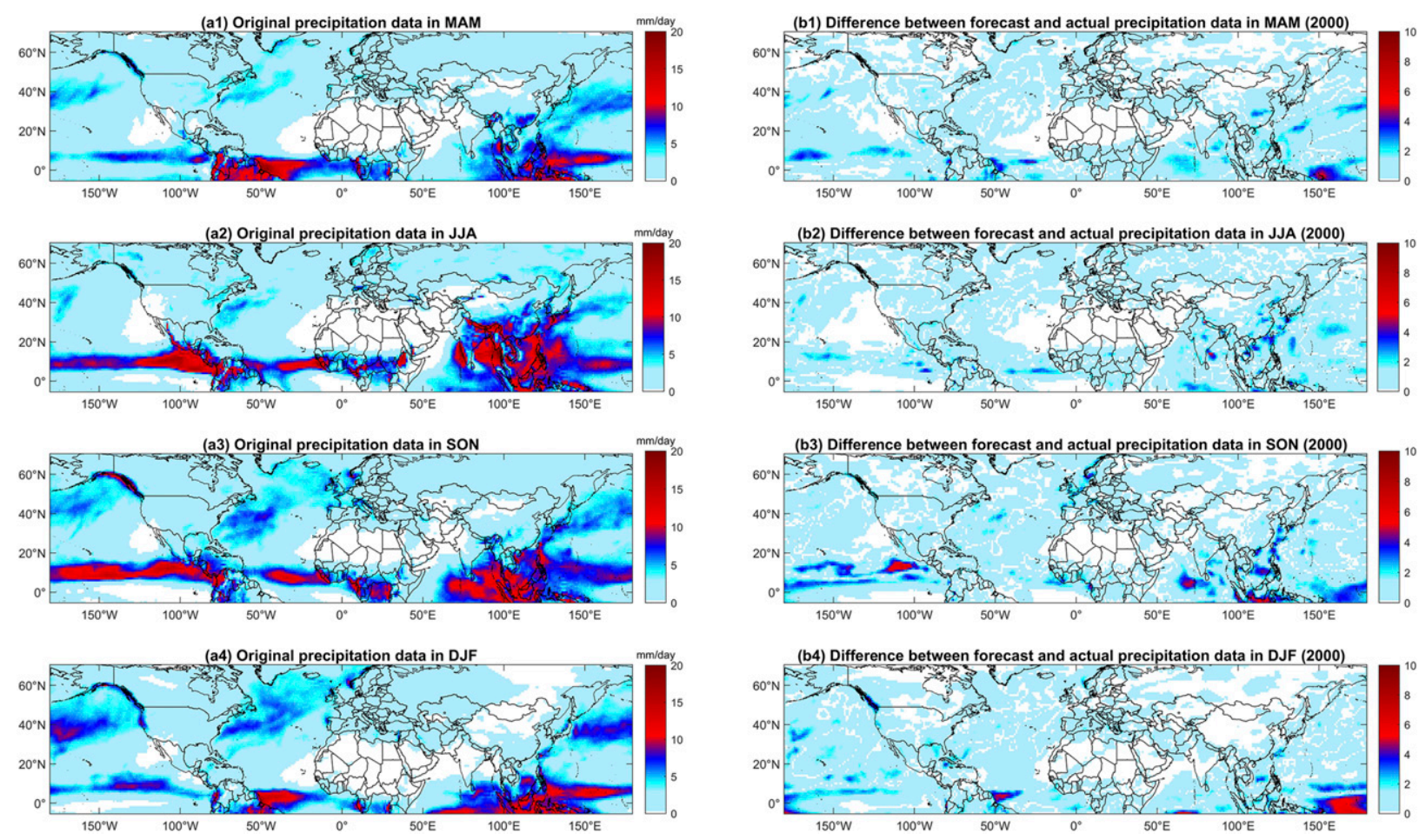

FIG. 11. Comparisons between model 4 forecast precipitation maps and original precipitation maps in 2000: (a1)-(a4) original precipitation data using CERA-20C in the MAM, JJA, SON, and DJF seasons and (b1)-(b4) absolute differences between forecast and actual precipitation in the MAM, JJA, SON, and DJF seasons. Annual data are mean value for each year using daily precipitation.

interannual and longer time scales, and this question is answered in the affirmative. The leading modes identified exhibit interannual variations at time scales and over epochs in the twentieth century that are consistent with those identified by other authors with known low-frequency climate modes (e.g., ENSO).

Acknowledgments. We are grateful to ECMWF for provision of the CERA-20C reanalysis dataset. Precipitation and IVT and SST are available at ECMWF CERA-20C (https:// apps.ecmwf.int/datasets/). The support provided by China Scholarship Council (201806270121) during a visit of Shida to Columbia University is acknowledged. This study was supported by the National Natural Science Foundation of China (51861125102), and the Natural Science Foundation of Hubei Province (2017CFA015). The authors thank the editor and the anonymous reviewers for their comments, which helped improve the quality of the paper.

\section{REFERENCES}

Beck, H. E., N. Vergopolan, M. Pan, V. Levizzani, and E. F. Wood, 2017: Global-scale evaluation of 22 precipitation datasets using gauge observations and hydrological modeling. Hydrol. Earth Syst. Sci., 21, 6201-6217, https://doi.org/10.5194/hess-216201-2017.

Bjerknes, J., 1969: Atmospheric teleconnections from the equatorial Pacific. Mon. Wea. Rev., 97, 163-172, https:// doi.org/10.1175/1520-0493(1969)097<0163:ATFTEP>2.3. $\mathrm{CO} ; 2$.
Castillo, R., R. Nieto, A. Drumond, and L. Gimeno, 2014: The role of the ENSO cycle in the modulation of moisture transport from major oceanic moisture sources. Water Resour. Res., 50, 1046-1058, https://doi.org/10.1002/2013WR013900.

Demšar, U., P. Harris, C. Brunsdon, A. S. Fotheringham, and S. McLoone, 2013: Principal component analysis on spatial data: An overview. Ann. Assoc. Amer. Geogr., 103, 106-128, https://doi.org/10.1080/00045608.2012.689236.

Efron, B., T. Hastie, L. Johnstone, and R. Tibshirani, 2004: Least angle regression. Ann. Stat., 32, 407-499, https://doi.org/ 10.1214/009053604000000067.

Ent, R., and H. Savenije, 2013: Oceanic sources of continental precipitation and the correlation with sea surface temperature. Water Resour. Res., 49, 3993-4004, https://doi.org/10.1002/ WRCR.20296.

Espinoza, V., D. Waliser, B. Guan, D. Lavers, and F. Ralph, 2018: Global analysis of climate change projection effects on atmospheric rivers. Geophys. Res. Lett., 45, 4299-4308, https:// doi.org/10.1029/2017G1076968.

Fischer, E. M., and R. Knutti, 2015: Anthropogenic contribution to global occurrence of heavy-precipitation and hightemperature extremes. Nat. Climate Change, 5, 560-564, https://doi.org/10.1038/nclimate2617.

Fisman, D., A. Tuite, and K. Brown, 2016: Impact of El Niño Southern Oscillation on infectious disease hospitalization risk in the United States. Proc. Natl. Acad. Sci. USA, 113, 14589 14 594, https://doi.org/10.1073/PNAS.1604980113.

Gao, Y., J. Lu, L. Leung, Q. Yang, S. Hagos, and Y. Qian, 2015: Dynamical and thermodynamical modulations on future changes of landfalling atmospheric rivers over western North America: Projections of atmospheric river changes. 
Geophys. Res. Lett., 42, 7179-7186, https://doi.org/10.1002/ $2015 \mathrm{Gl} 1065435$.

Gershunov, A., and D. Cayan, 2003: Heavy daily precipitation frequency over the contiguous United States: Sources of climatic variability and seasonal predictability. J. Climate, 16, 2752-2765, https://doi.org/10.1175/1520-0442(2003)016<2752: HDPFOT $>2.0 . \mathrm{CO} ; 2$.

— , T. Shulgina, F. Ralph, D. Lavers, and J. Rutz, 2017: Assessing the climate-scale variability of atmospheric rivers affecting western North America: Atmospheric river climate-scale behavior. Geophys. Res. Lett., 44, 7900-7908, https://doi.org/ 10.1002/2017G1074175.

— North America: The role of atmospheric rivers. Sci. Rep., 9, 9944, https://doi.org/10.1038/s41598-019-46169-w.

Gimeno, L., 2014: Oceanic sources of continental precipitation. Water Resour. Res., 50, 3647-3649, https://doi.org/10.1002/ 2014WR015477.

— A. Drumond, R. Nieto, R. Trigo, and A. Stohl, 2010: On the origin of continental precipitation. Geophys. Res. Lett., 37, L13804, https://doi.org/10.1029/2010G1043712.

_ - and Coauthors, 2012: Oceanic and terrestrial sources of continental precipitation. Rev. Geophys., 50, RG4003, https:// doi.org/10.1029/2012RG000389.

Greene, C. A., and Coauthors, 2019: The climate data toolbox for MATLAB. Geochem. Geophys. Geosyst., 20, 3774-3781, https://doi.org/10.1029/2019GC008392.

Grinsted, A., J. Moore, and S. Jevrejeva, 2004: Application of cross wavelet transform and wavelet coherence to geophysical time series. Nonlinear Processes Geophys., 11, 561-566, https:// doi.org/10.5194/NPG-11-561-2004.

Hagos, S., L. Leung, J.-H. Yoon, J. Lu, and Y. Gao, 2016: A projection of changes in landfalling atmospheric river frequency and extreme precipitation over western North America from the large ensemble CESM simulations. Geophys. Res. Lett., 43, 1357-1363, https://doi.org/10.1002/2015G1067392.

Hans, C., 2009: Bayesian lasso regression. Biometrika, 96, 835-845, https://doi.org/10.1093/biomet/asp047.

Holman, K., and S. Vavrus, 2012: Understanding simulated extreme precipitation events in Madison, Wisconsin, and the role of moisture flux convergence during the late twentieth and twenty-first centuries. J. Hydrometeor., 13, 877-894, https:// doi.org/10.1175/JHM-D-11-052.1.

Kamae, Y., W. Mei, S.-P. Xie, M. Naoi, and H. Ueda, 2017: Atmospheric rivers over the northwestern Pacific: Climatology and interannual variability. J. Climate, 30, 5605-5619, https:// doi.org/10.1175/JCLI-d-16-0875.1.

Knippertz, P., and H. Wernli, 2010: A Lagrangian climatology of tropical moisture exports to the Northern Hemispheric extratropics. J. Climate, 23, 987-1003, https://doi.org/10.1175/ 2009JCLI3333.1.

,$- \ldots$, and G. Gläser, 2013: A global climatology of tropical moisture exports. J. Climate, 26, 3031-3045, https://doi.org/ 10.1175/JCLI-D-12-00401.1.

Kobold, M., and K. Sušelj, 2005: Precipitation forecasts and their uncertainty as input into hydrological models. Hydrol. Earth Syst. Sci., 9, 322-332, https://doi.org/10.5194/hess-9-322-2005.

Kumar, A., L. Zhang, and W. Wang, 2013: Sea surface temperatureprecipitation relationship in different reanalyses. Mon. Wea. Rev., 141, 1118-1123, https://doi.org/10.1175/MWR-D-12-00214.1.

Labat, D., 2005: Recent advances in wavelet analyses: Part I. A review of concepts. J. Hydrol., 314, 275-288, https://doi.org/ 10.1016/j.jhydrol.2005.04.003.
Laloyaux, P., and Coauthors, 2018: CERA-20C: A coupled reanalysis of the twentieth century. J. Adv. Model. Earth Syst., 10, 1172-1195, https://doi.org/10.1029/2018MS001273.

Lavers, D., F. Ralph, D. Waliser, A. Gershunov, and M. Dettinger, 2015: Climate change intensification of horizontal water vapor transport in CMIP5. Geophys. Res. Lett., 42, 5617-5625, https://doi.org/10.1002/2015G1064672.

Leathers, D. J., B. Yarnal, and M. A. Palecki, 1991: The Pacific/ North American teleconnection pattern and United States climate. Part I: Regional temperature and precipitation associations. J. Climate, 4, 517-528, https://doi.org/10.1175/15200442(1991)004<0517:TPATPA > 2.0.CO;2.

Liu, P., L. Li, S. Guo, L. Xiong, W. Zhang, J. Zhang, and C.-Y. Xu, 2015: Optimal design of seasonal flood limited water levels and its application for the Three Gorges Reservoir. J. Hydrol., 527, 1045-1053, https://doi.org/10.1016/j.jhydrol.2015.05.055.

Lorente-Plazas, R., T. Mitchell, G. Mauger, and E. Salathé, 2018: Local enhancement of extreme precipitation during atmospheric rivers as simulated in a regional climate model. J. Hydrometeor., 19, 1429-1446, https://doi.org/10.1175/JHMD-17-0246.1.

Lu, M., and U. Lall, 2017: Tropical moisture exports, extreme precipitation and floods in northeastern US. Earth Sci. Res., 6, 91, https://doi.org/10.5539/esr.v6n2p91.

Ly, S., C. Charles, and A. Degré, 2013: Different methods for spatial interpolation of rainfall data for operational hydrology and hydrological modeling at watershed scale: A review. Biotechnol. Agron. Soc. Environ., 17, 392-406.

Mahoney, K., and Coauthors, 2016: Understanding the role of atmospheric rivers in heavy precipitation in the Southeast United States. Mon. Wea. Rev., 144, 1617-1632, https:// doi.org/10.1175/MWR-D-15-0279.1.

Mariotti, A., P. M. Ruti, and M. Rixen, 2018: Progress in subseasonal to seasonal prediction through a joint weather and climate community effort. npj Climate Atmos. Sci., 1, 4, https:// doi.org/10.1038/s41612-018-0014-z.

Meehl, G. A., J. M. Arblaster, and C. Tebaldi, 2005: Understanding future patterns of increased precipitation intensity in climate model simulations. Geophys. Res. Lett., 32, L18719, https:// doi.org/10.1029/2005G1023680.

Nakamura, J., U. Lall, Y. Kushnir, A. W. Robertson, and R. Seager, 2013: Dynamical structure of extreme floods in the U.S. Midwest and the United Kingdom. J. Hydrometeor., 14, 485-504, https://doi.org/10.1175/JHM-D-12-059.1.

Neiman, P., F. Ralph, G. Wick, J. Lundquist, and M. Dettinger, 2008a: Meteorological characteristics and overland precipitation impacts of atmospheric rivers affecting the west coast of North America based on eight years of SSM/I satellite observations. J. Hydrometeor., 9, 22-47, https://doi.org/10.1175/ 2007JHM855.1.

— river impacting the Pacific Northwest: Storm summary and offshore vertical structure observed with COSMIC satellite retrievals. Mon. Wea. Rev., 136, 4398-4420, https://doi.org/ 10.1175/2008MWR2550.1.

Nieto, R., R. Castillo, A. Drumond, and L. Gimeno, 2014: A catalog of moisture sources for continental climatic regions. Water Resour. Res., 50, 5322-5328, https://doi.org/10.1002/ 2013WR013901.

Ouyang, R., W. Liu, G. Fu, C. Liu, L. Hu, and H. Wang, 2014: Linkages between ENSO/PDO signals and precipitation, streamflow in China during the last 100 years. Hydrol. Earth Syst. Sci., 18, 3651-3661, https://doi.org/10.5194/hess-18-3651-2014. 
Pappenberger, F., K. J. Beven, N. M. Hunter, P. D. Bates, B. T. Gouweleeuw, J. Thielen, and A. P. J. de Roo, 2005: Cascading model uncertainty from medium range weather forecasts (10 days) through a rainfall-runoff model to flood inundation predictions within the European Flood Forecasting System (EFFS). Hydrol. Earth Syst. Sci., 9, 381-393, https://doi.org/ 10.5194/hess-9-381-2005.

Park, T., and G. Casella, 2008: The Bayesian lasso. J. Amer. Stat. Assoc., 103, 681-686, https://doi.org/10.1198/016214508000000337.

Payne, A., and G. Magnusdottir, 2015: An evaluation of atmospheric rivers over the North Pacific in CMIP5 and their response to warming under RCP 8.5. J. Geophys. Res. Atmos., 120, 11 173-11 190, https://doi.org/10.1002/2015JD023586.

Pendergrass, A. G., R. Knutti, F. Lehner, C. Deser, and B. M. Sanderson, 2017: Precipitation variability increases in a warmer climate. Sci. Rep., 7, 17966, https://doi.org/10.1038/ s41598-017-17966-y.

Peng, P., M. Halpert, S. Baxter, and M. Charles, 2019: Toward improving short-lead monthly forecast. Climate Prediction S\&T Digest, April 2019, NOAA/NWS, Silver Spring, MD, 164-165, https://doi.org/10.25923/ae2c-v522.

Perry, S. J., S. McGregor, A. S. Gupta, and M. H. England, 2017: Future changes to El Niño-Southern Oscillation temperature and precipitation teleconnections. Geophys. Res. Lett., 44, 10 608-10 616, https://doi.org/10.1002/2017GL074509.

Pierce, D. W., and Coauthors, 2013: Probabilistic estimates of future changes in California temperature and precipitation using statistical and dynamical downscaling. Climate Dyn., 40, 839856, https://doi.org/10.1007/s00382-012-1337-9.

Polade, S. D., D. W. Pierce, D. R. Cayan, A. Gershunov, and M. D. Dettinger, 2014: The key role of dry days in changing regional climate and precipitation regimes. Sci. Rep., 4, 4364, https:// doi.org/10.1038/srep04364.

—, A. Gershunov, D. R. Cayan, M. D. Dettinger, and D. W. Pierce, 2017: Precipitation in a warming world: Assessing projected hydro-climate changes in California and other Mediterranean climate regions. Sci. Rep., 7, 10783, https:// doi.org/10.1038/s41598-017-11285-y.

Räty, O., J. Räisänen, and J. S. Ylhäisi, 2014: Evaluation of delta change and bias correction methods for future daily precipitation: Intermodel cross-validation using ENSEMBLES simulations. Climate Dyn., 42, 2287-2303, https://doi.org/10.1007/ s00382-014-2130-8.
Rivera, E. R., F. Dominguez, and C. L. Castro, 2014: Atmospheric rivers and cool season extreme precipitation events in the Verde River basin of Arizona. J. Hydrometeor., 15, 813-829, https://doi.org/10.1175/JHM-D-12-0189.1.

Robertson, A. W., A. Kumar, M. Peña, and F. Vitart, 2015: Improving and promoting subseasonal to seasonal prediction. Bull. Amer. Meteor. Soc., 96, ES49-ES53, https://doi.org/ 10.1175/BAMS-D-14-00139.1.

Sang, Y.-F., 2013: A review on the applications of wavelet transform in hydrology time series analysis. Atmos. Res., 122, 8-15, https://doi.org/10.1016/j.atmosres.2012.11.003.

Shao, Z., H. Fu, D. Li, O. Altan, and T. Cheng, 2019: Remote sensing monitoring of multi-scale watersheds impermeability for urban hydrological evaluation. Remote Sens. Environ., 232, 111338, https://doi.org/10.1016/j.rse.2019.111338.

Steinschneider, S., and U. Lall, 2015: A hierarchical Bayesian regional model for nonstationary precipitation extremes in Northern California conditioned on tropical moisture exports. Water Resour. Res., 51, 1472-1492, https://doi.org/10.1002/ 2014WR016664.

Swain, D. L., B. Langenbrunner, J. D. Neelin, and A. Hall, 2018: Increasing precipitation volatility in twenty-first-century California. Nat. Climate Change, 8, 427-433, https://doi.org/ 10.1038/s41558-018-0140-y.

Tibshirani, R., 1996: Regression shrinkage and selection via the lasso. J. Roy. Stat. Soc., 58B, 267-288, https://www.jstor.org/ stable/2346178.

Torrence, C., and G. P. Compo, 1998: A practical guide to wavelet analysis. Bull. Amer. Meteor. Soc., 79, 61-78, https://doi.org/ 10.1175/1520-0477(1998)079<0061:APGTWA > 2.0.CO;2.

Trenberth, K. E., 2011: Changes in precipitation with climate change. Climate Res., 47, 123-138, https://doi.org/10.3354/ cr00953.

Viale, M., R. Valenzuela, R. Garreaud, and F. Ralph, 2018: Impacts of atmospheric rivers on precipitation in southern south America. J. Hydrometeor., 19, 1671-1687, https:// doi.org/10.1175/JHM-D-18-0006.1.

Zhu, Y., and R. Newell, 1994: Atmospheric rivers and bombs. Geophys. Res. Lett., 21, 1999-2002, https://doi.org/10.1029/ 94GL01710.

— atmospheric rivers. Mon. Wea. Rev., 126, 725-735, https:/doi.org/ 10.1175/1520-0493(1998)126<0725:APAFMF $>2.0 . C O ; 2$. 